\title{
Synthesis of Substituted Iptycenes
}

\section{Ying-Xian Ma \\ Zheng Meng \\ Chuan-Feng Chen*}

Beijing National Laboratory for Molecular Sciences, CAS Key Laboratory of Molecular Recognition and Function, Institute of Chemistry, Chinese Academy of Sciences, Beijing 100190, P. R. of China

cchen@iccas.ac.cn

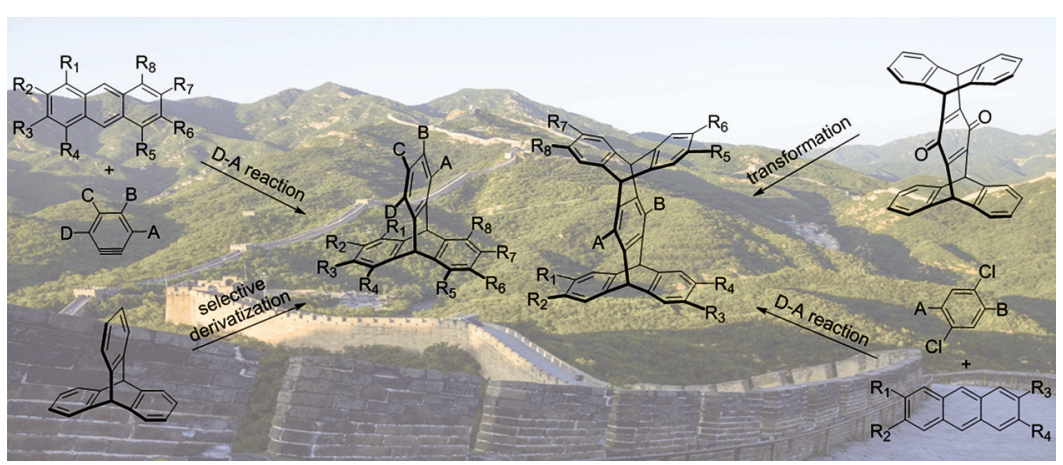

Received: 30.08.2014

Accepted after revision: 26.09.2014

Published online: 02.12 .2014

DOI: 10.1055/s-0034-1379361; Art ID: st-2014-a0728-a

Abstract Iptycenes are a class of aromatic compounds that contain several arene units fused to a bicyclo[2.2.2]octatriene bridgehead system. This unique, rigid, three-dimensional molecular structure provides several open electron-rich cavities with an abundance of reactive positions, and makes them useful for a wide range of applications. There is no doubt that the synthesis and reactions of iptycene derivatives with different functional groups form the fundamental basis of iptycene development. In this account, the synthesis of substituted iptycenes is described. In particular, the different synthetic strategies toward substituted triptycenes and pentiptycenes are the main focus.

1 Introduction

2 Synthesis of Substituted Triptycenes

2.1 Direct Diels-Alder Addition Reactions

2.2 Selective Substitution of the Triptycene Skeleton

2.2.1 Acetylation

2.2.2 Nitration

2.2.3 Halogenation

3 Synthesis of Substituted Pentiptycenes

4 Synthesis of Other Substituted Iptycenes

5 Conclusion and Outlook

Key words acylation, Diels-Alder reaction, electrophilic addition, halogenation, substituent effects

\section{Introduction}

In 1942, Bartlett and co-workers ${ }^{1}$ reported triptycene as the first and simplest member of the iptycene family. From then on, the synthesis and reactions of iptycenes and their derivatives, in addition to their potential applications in many research areas, began to receive more and more attention. ${ }^{2}$ As a class of aromatic compounds, iptycenes contain several arene units fused to a bicyclo[2.2.2]octatriene bridgehead system, with each plane of the arene separated from the others by this bridgehead system, while being connected through bridgehead carbons. ${ }^{2 a, 3}$ This unique, rigid, three-dimensional molecular structure provides several open electron-rich cavities with an abundance of reactive positions, and makes them useful for a wide range of applications. Over the past 70 years of iptycene chemistry, especially the last two decades, a large number of applications with iptycenes and their derivatives in molecular machines, ${ }^{4}$ supramolecular chemistry, ${ }^{2 f, 5}$ materials science, ${ }^{6}$ sensor applications ${ }^{7}$ and many other research areas ${ }^{5 f, 8}$ have been discovered. However, the development of applications for iptycenes cannot be separated from the synthesis of iptycene derivatives with different functional groups, which undoubtedly forms the fundamental basis behind the future development of iptycenes. In this account, the synthesis of substituted iptycenes is described. In particular, the different synthetic strategies toward substituted triptycenes and pentiptycenes are mainly focused upon. Moreover, some representative examples of the syntheses of heptiptycene and noniptycene derivatives are also described. We hope this account will help inspire the further development of iptycene chemistry.

\section{Synthesis of Substituted Triptycenes}

Triptycene, with three phenyl rings being connected via two bridgehead carbons, has an abundance of reactive sites which are amenable to functionalization. Its unique structure makes triptycene derivatives useful for a wide range of potentially useful applications. There are two main synthetic strategies for the preparation of substituted triptycenes: (1) via the direct Diels-Alder addition reaction between the corresponding substituted anthracene and a benzyne, and (2) via the selective derivatization of unsubstituted triptycene (1) (Scheme 1). 
<smiles>[R]c1cc2cc3c(P)c([R7])c([2H])c([R])c3cc2c([R7])c1[R]</smiles><smiles>Cc1c(O)ccc(I)c1[18O]</smiles>
$\mathrm{R}^{5}$ 6

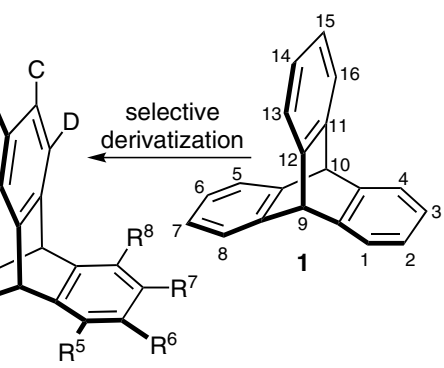

Scheme 1 Two synthetic strategies for the synthesis of substituted triptycenes

\subsection{Direct Diels-Alder Addition Reactions}

In 1956, Wittig and Ludwig ${ }^{9}$ pioneered a convenient method for the synthesis of triptycene (1) via the DielsAlder addition reaction between benzyne and anthracene. Obviously, this strategy provides a direct and convenient method for the synthesis of triptycenes with different functional groups.

The simple Diels-Alder cycloaddition of an in situ generated mono-, di- or tetra-substituted aryne to anthracene gave the corresponding substituted triptycene. Consequently, Cadogan and co-workers ${ }^{10}$ synthesized mono- and di-tert-butyl-substituted triptycenes $\mathbf{2}$ and $\mathbf{3}$ via the addition reaction of anthracene to the corresponding tert-butylsubstituted aryne, which was itself formed by the heterolytic cleavage of $o$-tert-butyl- $N$-nitrosoacetanilide in benzene (Scheme 2). In 1968, Heaney and co-workers ${ }^{11}$ reacted tetrafluoro- and tetrachloro-benzynes, which were generated from the corresponding pentahalo-aryl Grignard re-

\section{Biographical Sketches}
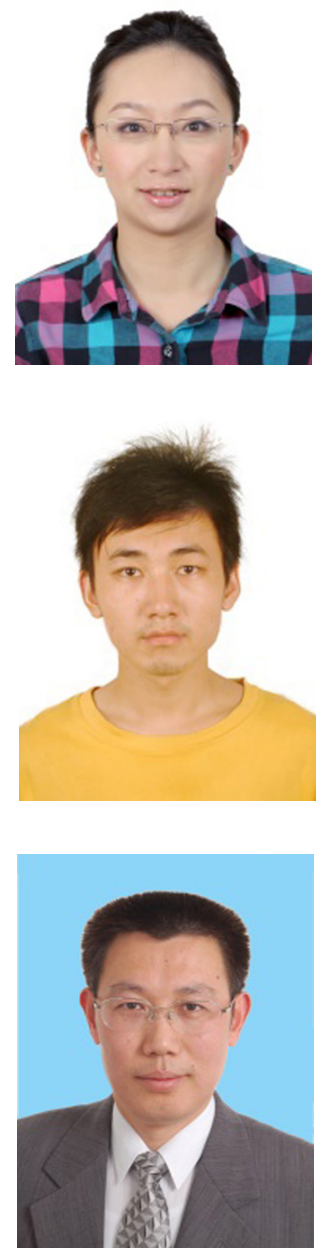

Ying-Xian Ma obtained her B.S. degree from Nankai University in 2010. She then joined the laboratory of Professor ChuanFeng Chen at ICCAS to pursue her Ph.D. Her current research is focused on pentiptycene-based supramolecular chemistry.

on triptycene-derived synthetic hosts.
Zheng Meng obtained his B.S. Science and Technology Beijing in 2011. He then joined the lab- oratory of Professor ChuanFeng Chen at ICCAS to pursue his Ph.D. His research is focused on molecular machines based
Chuan-Feng Chen was born in Anhui, China in 1965. He graduated and then received his Ph.D. degree from Nanjing University in 1994. After working as a postdoctoral fellow at ICCAS for two years, he became an associate professor at the same institute in 1996. From 1998 to
2001, he worked as a visiting scientist at the University of New Mexico. He was then promoted to a full professor at ICCAS in 2001. His current research interests are mainly focused on supramolecular chemistry based on novel synthetic hosts, and helicene chemistry.
Beijing National Laboratory for Molecular Sciences, CAS Key Laboratory of Molecular Recognition and Function, Institute of Chemistry, Chinese Academy of Sciences, Beijing 100190, P. R. of China. 
a)<smiles>CC1=CC=[C+][C+](C(C)(C)C)C1=NOC(=O)Nc1ccccc1C(C)(C)C</smiles><smiles>CCCCCCc1ccccc1C(C)(C)C</smiles>

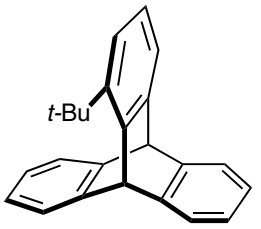

2

b)<smiles>CN(OC(=O)N(c1cc(C(C)(C)C)ccc1C(C)(C)C)c1cc(C(C)(C)C)ccc1C(C)(C)C)C(C)(C)C</smiles><smiles></smiles>

3

Scheme 2 Synthesis of tert-butyl substituted triptycenes

agents, with anthracene to obtain the tetrahalogenated triptycenes $\mathbf{4}$ and 5 in reasonable $42 \%$ and 54\% yields (Scheme 3).

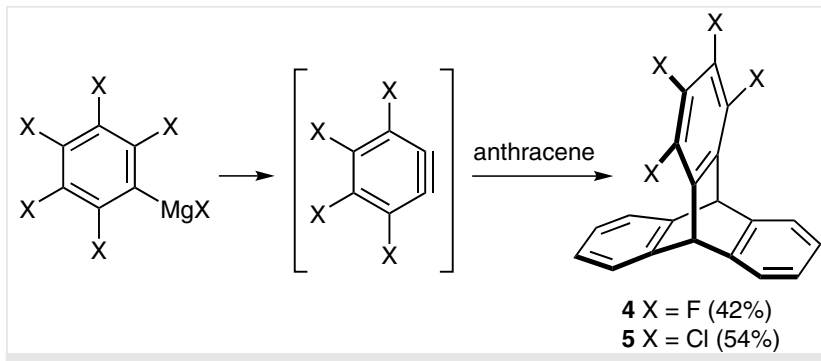

Scheme 3 Synthesis of tetrahalogenated triptycenes

With the development of methods for the generation of benzyne and arynes, a significant number of triptycenes possessing various functional groups, even aryltriptycene derivatives, could be obtained in satisfactory yields. By modifying the reaction conditions described by Cadogan, ${ }^{12}$ Anzenbacher and co-workers ${ }^{13}$ synthesized the corresponding di(thien-2-yl)triptycene 7 in $87 \%$ yield via the addition reaction of di(thien-2-yl)benzyne, which was gener- ated in situ from 3-halo-1,4-bis(thien-2-yl)benzene $\mathbf{6}$ in the presence of potassium tert-butoxide ( $t$-BuOK), with anthracene (Scheme 4).
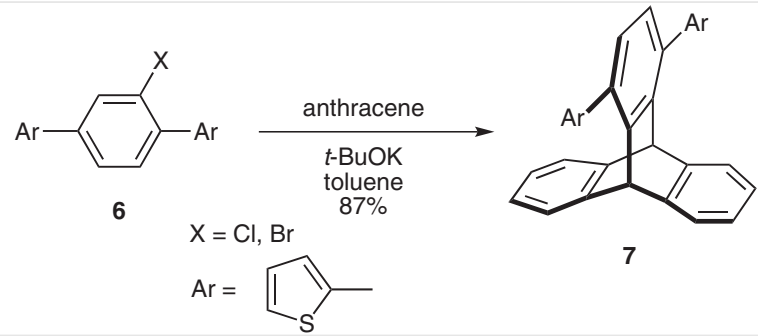

Scheme 4 Synthesis of di(thien-2-yl)triptycene 7

Making use of substituted anthracenes instead of substituted arynes, the corresponding substituted triptycenes were obtained via Diels-Alder reactions. For example, the Diels-Alder addition reaction between chlorobenzyne and anthracene gave mono-chlorotriptycene in $16 \%$ yield. Under similar reaction conditions, a yield of up to $30 \%$ of the corresponding mono-chlorotriptycene could be obtained via the Diels-Alder addition of benzyne with a chloroanthracene. ${ }^{14}$ However, the aryne also reacts with the other aromatic rings of the anthracene leading to the generation of different addition isomers. Klanderman and Criswell ${ }^{15}$ investigated the relative reactivity of 1,4-disubstitued anthracenes toward benzyne. In the one-pot Diels-Alder reaction between benzyne and a 1,4-disubstituted anthracene (end-ring substituents), there were three anthracene-benzyne adducts which could be detected (Scheme 5). Generally speaking, benzyne prefers to react with the B ring (center ring) to form triptycene 8a as the major adduct. However, the nature of the substituents would influence the ratio of the $\mathrm{B}$ ring to $\mathrm{A}$ ring and/or $\mathrm{C}$ ring adducts. The relative proportion of adduct $\mathbf{8 b}$ would increase markedly in the presence of electron-donating substituents on ring A, but would decrease if electron-withdrawing substituents were present on the same ring. However, different substituents on the A ring have no marked influence on the reactivity of the $B$ ring toward benzyne.

The Diels-Alder reaction between different substituted anthracenes and a substituted benzyne would give access to more diverse substituted triptycene derivatives, such as symmetrical tri-, hexa-, octa- and even dodeca-substituted triptycenes.

In 1971, Kadosaka and co-workers ${ }^{14}$ reported the synthesis of a series of symmetrical trichloro-substituted triptycenes. As shown in Scheme 6, 1,5-dichloroanthracene (9) reacted with 3-chlorobenzyne, generated in situ from 6- 


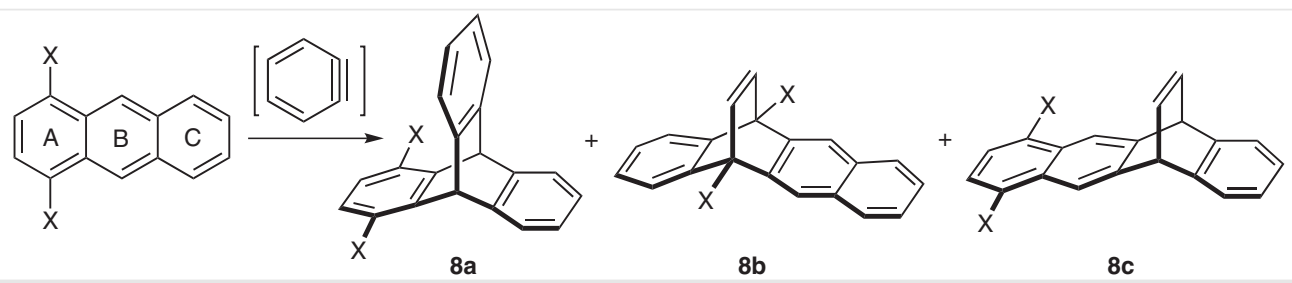

Scheme 5 The reaction between 1,4-disubstituted anthracenes and benzyne

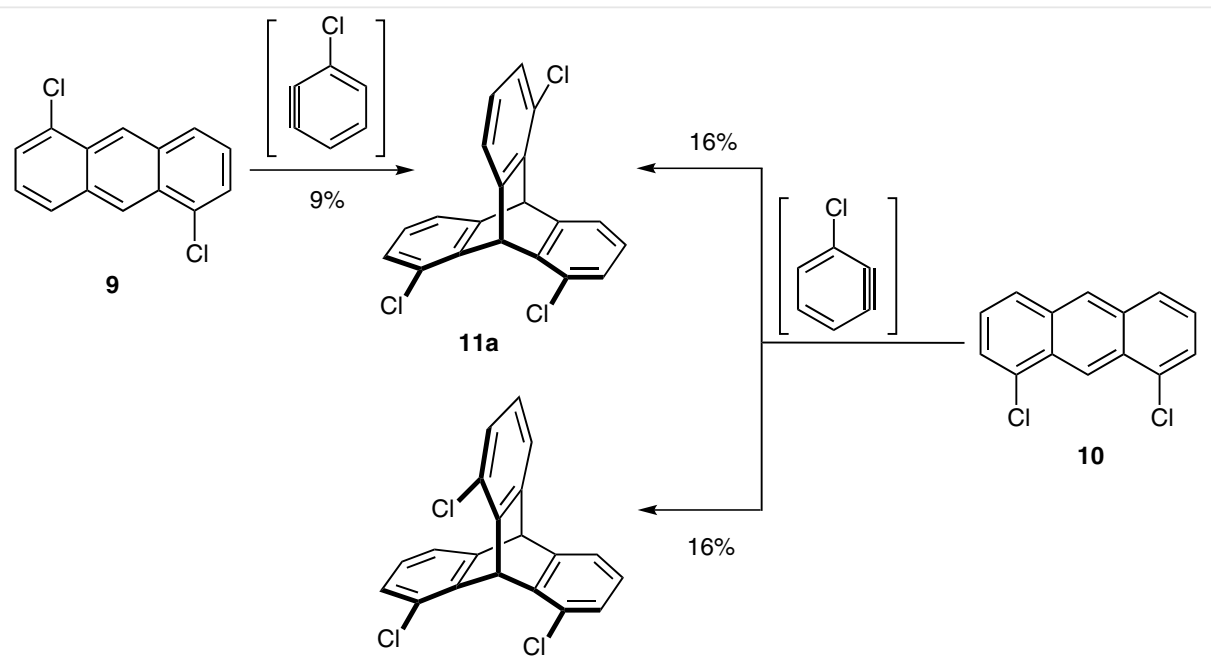

11b

Scheme 6 Synthesis of symmetrical trichloro-substituted triptycenes

chloroanthranilic acid, to provide 1,8,16-trichlorotriptycene (11a) in 9\% yield. A similar Diels-Alder reaction of 1,8dichloroanthracene (10) with 3-chlorobenzyne in dimethoxymethane also gave 1,8,16-trichlorotriptycene (11a) as the anti adduct, along with the generation of the syn adduct, 1,8,13-trichlorotriptycene (11b).

According to Kadosaka's synthetic strategy, ${ }^{14}$ and with some improvements to the reaction conditions, Rogers and Averill ${ }^{16}$ subsequently synthesized a series of symmetrical trisubstituted triptycenes. Moreover, they further investigated the influence of the substituents on the anthracene and benzyne on the anti to syn isomer ratios of the trisubstituted triptycenes. As shown in Table 1, the nature of the substituents on the benzyne had a significant effect on the observed regiochemistry of the Diels-Alder reaction. When $\mathrm{R}^{\prime}=\mathrm{Me}$, the syn isomer was the major adduct; the yield was two or three times that of the anti isomer. When $\mathrm{R}^{\prime}=\mathrm{Cl}$, the situation was the other way around, in which the anti adduct was the major product with over a 3:1 ratio relative to the syn isomer. These results are interpreted as the simple electrostatic matching of the polarized benzyne and anthracene orbitals to determine the major adduct. However, when $\mathrm{R}^{\prime}=\mathrm{CO}_{2} \mathrm{Me}$, the situation became much more complicated, with the nature of the $\mathrm{R}$ substituent on the anthracene playing the dominant role in dictating the observed regiochemistry of the adducts. This result revealed an increased sensitivity to subtle changes imparted by the substituents on the anthracene, which were probably caused by the methoxycarbonyl substituent inducing polarization of the benzyne $\pi$ electrons. In contrast with the marked influence from the electrostatic nature of the substituents, there were no obvious steric effects due to the substituents on the isomeric ratios.

In 2005, we $\mathrm{e}^{5 \mathrm{c}}$ synthesized 2,3,6,7,14,15-hexamethoxytriptycene (12) in 65\% yield via the Diels-Alder reaction of 2,3,6,7-tetramethoxy-9,10-dimethylanthracene and dimethoxybenzyne, generated from 4,5-dimethoxybenzenediazonium-2-carboxylate, in 1,2-dichloroethane (Scheme 7). This hexasubstituted triptycene adopts a perfect $D_{3 h}$ symmetry, which was revealed by the simple signals present in the ${ }^{1} \mathrm{H}$ and ${ }^{13} \mathrm{C}$ NMR spectra. Moreover, treatment of 0 -dimethoxysubstituted triptycene with dilute nitric acid gave triptycene 0 -quinone instead of the nitration product. ${ }^{17}$ As shown in Scheme 7, hexamethoxytriptycene $\mathbf{1 2}$ could be oxidized selectively in $89 \%$ yield by dilute nitric acid $(0.25 \mathrm{M})$ to give triptycene mono(o-quinone) 13a in 30 minutes. When the molarity of the dilute nitric acid was increased to $1.25 \mathrm{M}$, triptycene bis(o-quinone) $\mathbf{1 3 b}$ was obtained as a dark red solid in a high $87 \%$ yield. However, triptycene tri(o-qui- 
Table 1 The Ratios of the anti/syn Isomers of Trisubstituted Triptycenes

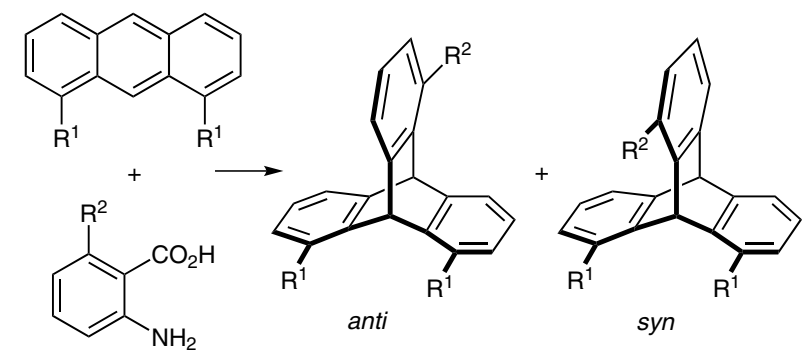

\begin{tabular}{llllll}
\hline Entry & $\mathrm{R}^{1}$ & $\mathrm{R}^{2}$ & anti (\%) & syn (\%) & Yield (\%) \\
\hline 1 & $\mathrm{Cl}$ & $\mathrm{Me}$ & 25 & 75 & 74 \\
2 & $\mathrm{CN}$ & $\mathrm{Me}$ & 28 & 72 & 57 \\
3 & $\mathrm{CO}_{2} \mathrm{Me}$ & $\mathrm{Me}$ & 31 & 69 & 58 \\
4 & $\mathrm{Cl}$ & $\mathrm{Cl}$ & 77 & 23 & 27 \\
5 & $\mathrm{CO}_{2} \mathrm{Me}$ & $\mathrm{Cl}$ & 73 & 27 & 20 \\
6 & $\mathrm{Cl}$ & $\mathrm{CO}_{2} \mathrm{Me}$ & 44 & 56 & 47 \\
7 & $\mathrm{CN}$ & $\mathrm{CO}_{2} \mathrm{Me}$ & 99 & 1 & 38 \\
8 & $\mathrm{CO}_{2} \mathrm{Me}$ & $\mathrm{CO}_{2} \mathrm{Me}$ & 76 & 24 & 62 \\
\hline
\end{tabular}

none) could not be obtained by the oxidation of hexamethoxytriptycene $\mathbf{1 2}$, probably due to the instability of the product.

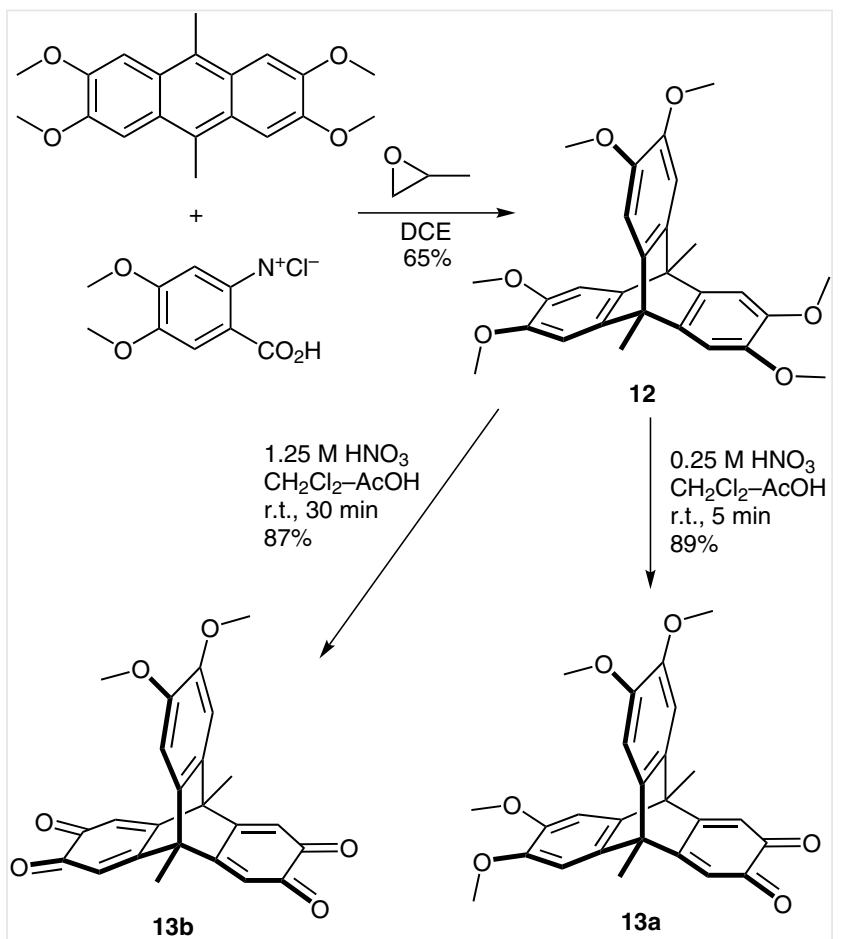

Scheme 7 Synthesis and further oxidation of 2,3,6,7,14,15-hexamethoxytriptycene (12)
Gottlieb, Biali and co-workers ${ }^{18}$ have reported the Diels-Alder reaction between 1,2,3,4,5,6,7,8-octaethylanthracene and dimethylbenzyne (prepared from 3,6-dimethylbenzenediazonium-2-carboxylate hydrochloride), in the presence of propylene oxide in 1,2-dichloroethane at reflux temperature over seven days, which gave $1,2,3,4,5,6,7,8$-octaethyl-13,16-dimethyltriptycene (14) in 67\% yield. Theoretically speaking, octaethyltriptycene $\mathbf{1 4}$ has eight possible conformers with different 'up' or 'down' arrangements of the ethyl groups. In fact, octaethyltriptycene $\mathbf{1 4}$ prefers to be in the fully alternate conformation 14a (Figure 1) in solution, which has the lowest calculated (MM3) steric energy. However, in the solid state, octaethyltriptycene $\mathbf{1 4}$ adopts the alternative higher energy conformation 14b (Figure 1), in which a pair of vicinal ethyl groups is oriented in the same direction. This can be rationalized in terms of packing forces.
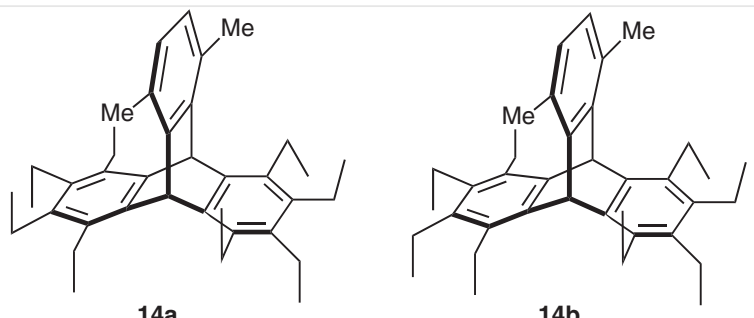

Figure 1 Two conformers of octaethyltriptycene 14

Moreover, Závada and co-workers ${ }^{19}$ obtained a series of methyltriptycenes $\mathbf{1 5}$ starting from various methylanthracenes and appropriate arynes, which were generated in situ from anthranilic or methylanthranilic acid. Next, oxidation of the methyl groups with potassium permanganate $\left(\mathrm{KMnO}_{4}\right)$ gave the corresponding triptycene carboxylic acids $\mathbf{1 6}$ in very good yields (Table 2 ). It was worth noting that the fully oxidized product of hexamethyltriptycene could not be obtained using potassium permanganate as the only oxidant; the use of strongly basic potassium permanganate resulted in the formation of over-oxidation side products. Zonta et al. ${ }^{20}$ carried out this oxidation reaction with potassium permanganate in pyridine and an aqueous solution of sodium hydroxide ( $\mathrm{NaOH})$, and obtained the desired hexacarboxylic acid in $78 \%$ yield.

With this direct Diels-Alder reaction strategy, Pascal and co-workers ${ }^{21}$ have successfully obtained the most crowded triptycene derivative to date, 1,2,3,4,5,6,7,8,13,14,15,16-dodecaphenyltriptycene (17). They utilized 3,4,5,6-tetraphenylanthranilic acid as the benzyne precursor, with the in situ generated 3,4,5,6-tetraphenylbenzyne reacting with 1,2,3,4,5,6,7,8-octaphenylanthracene in 1,2-dichloroethane at reflux temperature to give the sterically crowded triptycene derivative $\mathbf{1 7}$ in $11 \%$ yield (Scheme 8). This comparatively low yield was probably due to steric hindrance caused by the relatively large number of phenyl groups. 
Table 2 Synthesis of Triptycene Carboxylic Acids

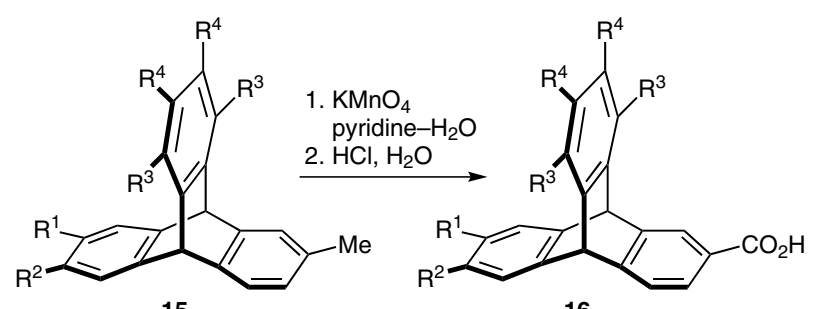

15

16

\begin{tabular}{llll}
\hline Entry & 15 & 16 & $\begin{array}{l}\text { Yield } \\
(\%)\end{array}$ \\
\hline 1 & $R^{1}=R^{3}=R^{4}=H, R^{2}=M e$ & $R^{1}=R^{3}=R^{4}=H, R^{2}=\mathrm{CO}_{2} H$ & 87 \\
2 & $R^{2}=R^{3}=R^{4}=H, R^{1}=M e$ & $R^{2}=R^{3}=R^{4}=H, R^{1}=\mathrm{CO}_{2} H$ & 95 \\
3 & $R^{1}=R^{4}=H, R^{2}=R^{3}=M e$ & $R^{1}=R^{4}=H, R^{2}=R^{3}=\mathrm{CO}_{2} H$ & 97 \\
4 & $R^{2}=R^{4}=H, R^{1}=R^{3}=M e$ & $R^{2}=R^{4}=H, R^{1}=R^{3}=\mathrm{CO}_{2} H$ & 94 \\
5 & $R^{1}=R^{3}=H, R^{2}=R^{4}=M e$ & $R^{1}=R^{3}=H, R^{2}=R^{4}=\mathrm{CO}_{2} H$ & 94 \\
6 & $R^{2}=R^{3}=H, R^{1}=R^{4}=M e$ & $R^{2}=R^{3}=H, R^{1}=R^{4}=\mathrm{CO}_{2} H$ & 86
\end{tabular}

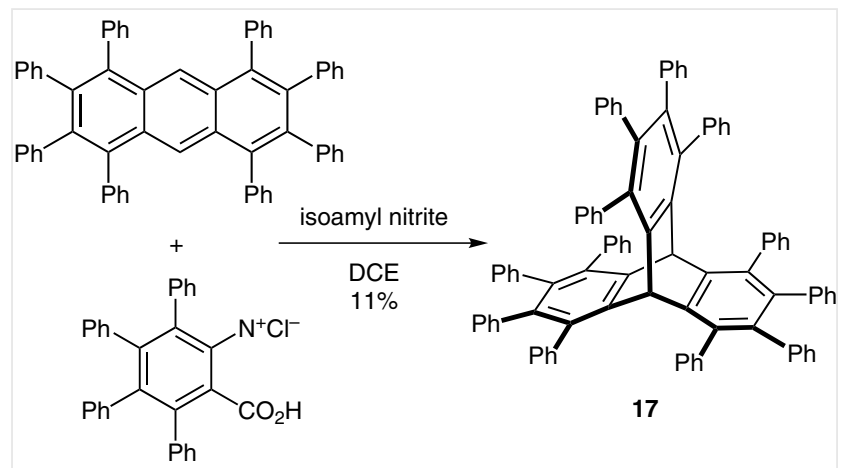

Scheme 8 Synthesis of 1,2,3,4,5,6,7,8,13,14,15,16-dodecaphenyltriptycene (17)

\subsection{Selective Substitution of the Triptycene Skele- ton}

By employing the direct Diels-Alder reaction strategy, a wide range of substituted triptycene derivatives have been synthesized in reasonable yields, and in some cases, in relatively high yields. However, there are three notable deficiencies that restrict this synthetic strategy: (1) the DielsAlder reactions between arynes and substituted anthracenes are complicated by the formation of the respective positional isomers, which results in decreased reaction yields and the necessity for (and associated difficulties in- volved with) separation of the desired products, (2) many substituted anthracenes were obtained in low yields over several reaction steps, which is not economical or practical, and (3) the triple bond in the benzyne or aryne is not a typical $\pi$ bond and is highly reactive, hence the benzyne or aryne has to be produced in situ in order for it to be able to participate in the Diels-Alder reaction. The reactivity of the benzyne or aryne precursor plays the dominant role in the final yield of the Diels-Alder reaction. Moreover, there are benzynes or arynes with certain substituents that are difficult to generate in situ in high yields. Thus, additional convenient routes to obtain substituted triptycene derivatives in high yields are necessary.

As we mentioned previously, unsubstituted triptycene $\mathbf{1}$ can be synthesized in over $75 \%$ yield by a one-step DielsAlder reaction, in which anthranilic acid acted as the benzyne precursor. ${ }^{22}$ In addition, the starting materials are inexpensive and commercially available, hence unsubstituted triptycene $\mathbf{1}$ can be produced in large quantities. Thus, the selective derivatization of unsubstituted triptycene 1 represents an efficient and alternative route to the synthesis of specific substituted triptycene derivatives.

\subsubsection{Acetylation}

It is common knowledge that acyl groups, especially formyl and acetyl groups, are important functional groups in organic synthesis. Various other useful organic functional groups, such as cyano, ethynyl, acetamino and acetoxy groups can be easily generated from acyl groups.

In 1965, Parget and Burger ${ }^{23}$ reported the first example of the direct electrophilic substitution of triptycene. When a mixture of triptycene (1) and anhydrous aluminum chloride in tetrachloroethane was treated with an equivalent amount of acetyl chloride at -20 to $-30^{\circ} \mathrm{C}, 2$-acetyltriptycene (18) was obtained in $97 \%$ yield after work-up (Scheme 9a).

It is worth noting that this Friedel-Crafts acetylation occurs preferentially at the $\beta$-position of the aromatic ring of triptycene (1). Starting from 2-acetyltriptycene (18), Skvarchenko and co-workers ${ }^{24}$ obtained the unsaturated hydrocarbons of the triptycene series, 2-vinyltriptycene (19) and 2-ethynyltriptycene (20) (Scheme 9b).

Using similar methodology, Skvarchenko and co-workers $^{24}$ reacted triptycene (1) with benzoyl chloride or fumaroyl chloride in the presence of nitromethane, and obtained the corresponding $\beta$-substituted products $\mathbf{2 1}$ and 22, respectively (Scheme 10). 
a)

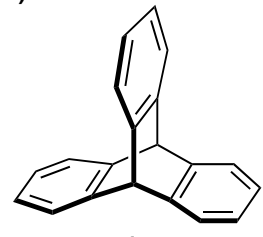

1

b)

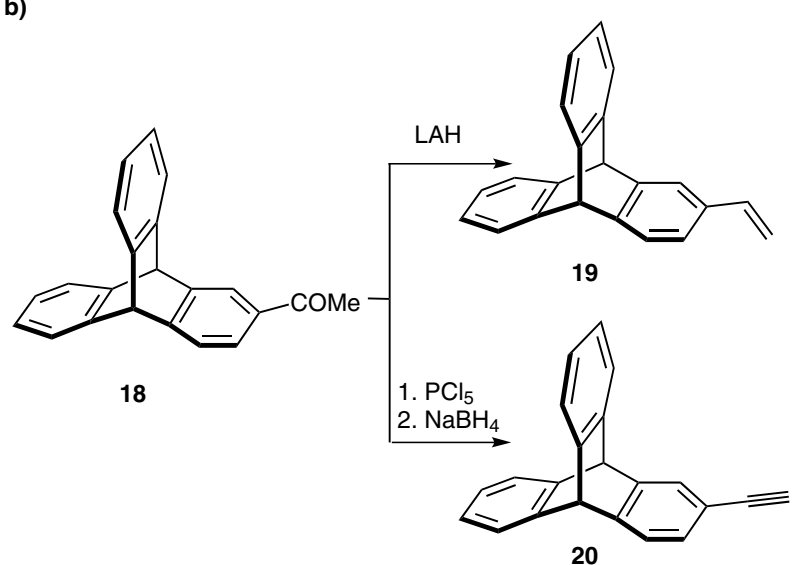

Scheme 9 Synthesis of 2-acetyltriptycene (18), 2-vinyltriptycene (19) and 2-ethynyltriptycene (20)

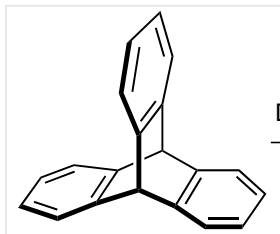

1

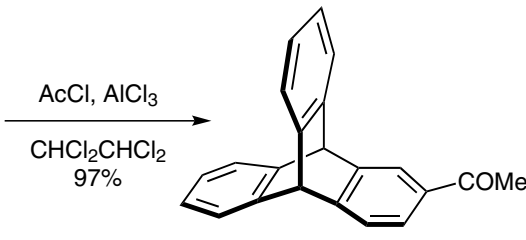

18 a)

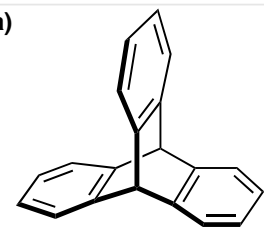

1

b)

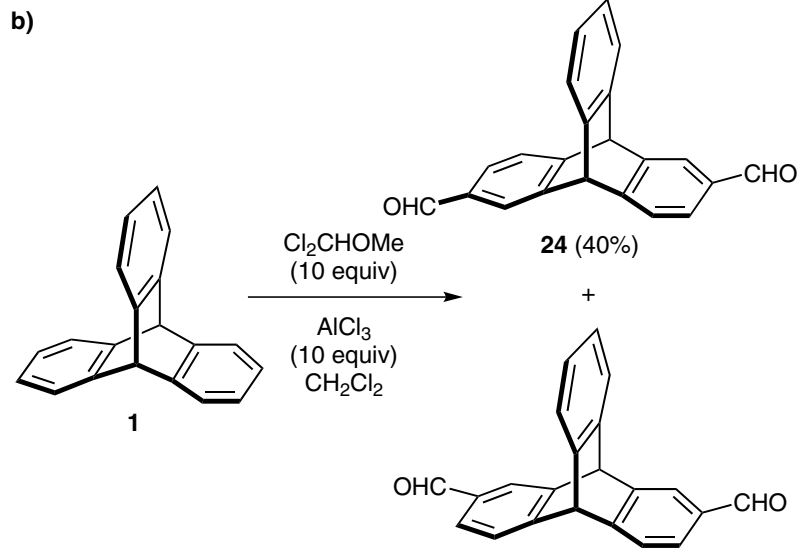

25 (37\%)

c)

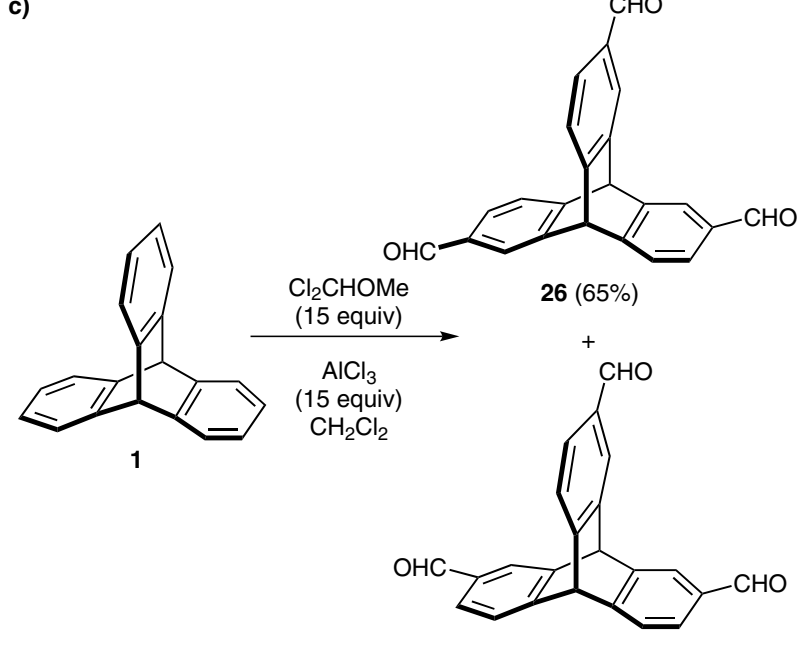

1

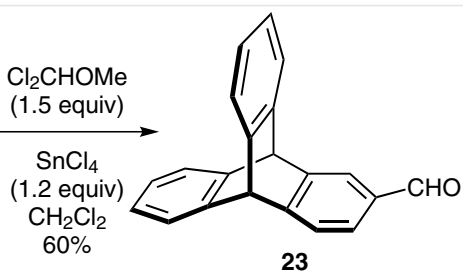

23
$27(20 \%)$

Scheme 11 Selective formylations of triptycene (1)

In 2012, when we attempted the selective synthesis of formyltriptycene, we found that this aluminum chloride catalyzed Friedel-Crafts acylation of triptycene did not stop at the mono- or di-formylated stage. ${ }^{25}$ Further studies showed that treatment of triptycene (1) with 1.5 equivalents of dichloro(methoxy)methane and 1.2 equivalents of stannic chloride $\left(\mathrm{SnCl}_{4}\right)$ in dichloromethane at $0{ }^{\circ} \mathrm{C}$, for one hour, gave selectively 2 -formyltriptycene (23) in $60 \%$ yield (Scheme 11a). This Friedel-Crafts formylation did not occur 

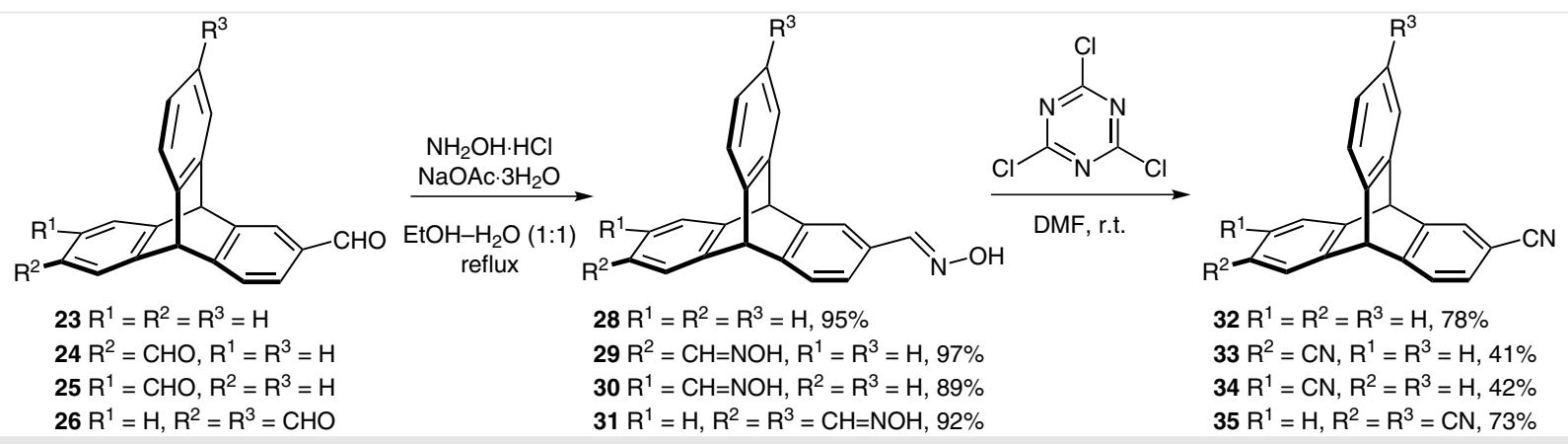

Scheme 12 The transformation of formyl- to cyano-substituted triptycenes

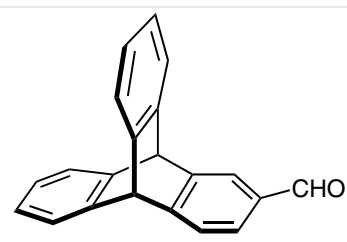

23

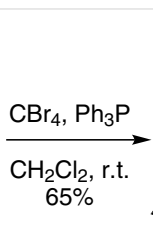

\%

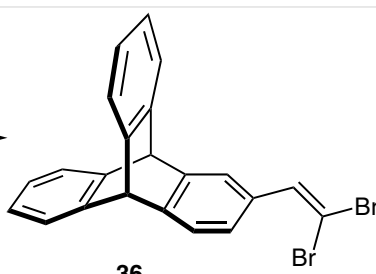

36

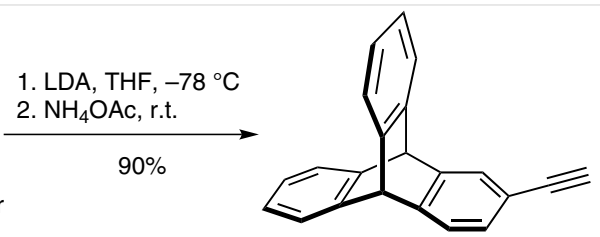

20

Scheme 13 Corey-Fuchs reaction of 2-formyltriptycene

further, even in the presence of increased amounts of stannic chloride and at higher reaction temperatures. With aluminum chloride, the formylation proceeded differently from that employing stannic chloride. Hence, the diformylated products, 2,6-diformyltriptycene (24) and 2,7-diformyltriptycene (25), could be obtained by the formylation of $\mathbf{1}$ with 10 equivalents of dichloro(methoxy)methane and 10 equivalents of aluminum chloride in dichloromethane at $-15{ }^{\circ} \mathrm{C}$ overnight, and bubbling hydrogen chloride into the system (Scheme 11b). When the amounts of dichloro(methoxy)methane and aluminum chloride were increased further, a pair of triformyltriptycene isomers was obtained. Treatment of triptycene (1) with 15 equivalents of dichloro(methoxy)methane in the presence of 15 equivalents of aluminum chloride gave 2,6,14-triformyltriptycene (26) and 2,7,14-triformyltriptycene (27) in $65 \%$ and $20 \%$ yield, respectively (Scheme 11c).

With these formyl-substituted triptycenes in hand, we next investigated the transformation of the formyl group into other useful functional groups. When formyl-substituted triptycenes 23-26 were treated with hydroxylamine hydrochloride (1.2 mmol per formyl group) and sodium acetate trihydrate ( $1.5 \mathrm{mmol}$ per formyl group) in a mixture of ethanol and water $(1: 1 \mathrm{v} / \mathrm{v})$ at reflux temperature for 12 hours, the corresponding oxime-substituted triptycenes 28-31 were obtained in yields over $90 \%$. These oximes could be dehydrated by using 2,4,6-trichloro-1,3,5-triazine (1.1 mmol per oxime group) in $\mathrm{N}, \mathrm{N}$-dimethylformamide (DMF) at room temperature to give cyano-substituted triptycene derivatives 32-35 in $41-78 \%$ yields (Scheme 12). The Corey-Fuchs reaction of 2-formyltriptycene (23) with carbon tetrabromide and triphenylphosphine in dichloromethane gave dibromovinyltriptycene $\mathbf{3 6}$ in $65 \%$ yield. Subsequent reaction of $\mathbf{3 6}$ with lithium diisopropylamide produced 2-ethynyltriptycene (20) in 90\% isolated yield (Scheme 13).

Selective acetylation of triptycene (1), such as by formylation, can be realized with different amounts of the acetylation reagent and aluminum chloride. In the presence of one equivalent of aluminum chloride, triptycene $(\mathbf{1})$ reacted with 1.5 equivalents of acetyl chloride over one hour to give 2 -acetyltriptycene (18) in 84\% yield (Scheme 14a).

When the amounts of acetyl chloride and aluminum chloride were increased to 2.5 equivalents and two equivalents, respectively, bis-acetylation of triptycene occurred to produce 2,6-diacetyltriptycene (37) and 2,7-diacetyltriptycene (38) in yields of 38\% and 35\% (Scheme 14b). Moreover, this same acetylation procedure afforded 2,6,14-triacetyltriptycene (39) and 2,7,14-triacetyltriptycene (40), when triptycene (1) was treated with six equivalents of acetyl chloride and five equivalents of aluminum chloride in dichloromethane (Scheme 14c). In either the formylation or acetylation of triptycene, a roughly $1: 1$ ratio of the diacylated product could be obtained, while the ratios of the transand cis-triacylated triptycenes were $3: 1$, which is consistent with statistics. It is worth noting that the mono-acylation of triptycene preferred to occur at the $\beta$-position of the benzene ring, and that the additional acylations to give diand tri-substituted products also occurred at the $\beta$-positions. 


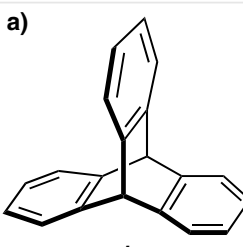

1

b)
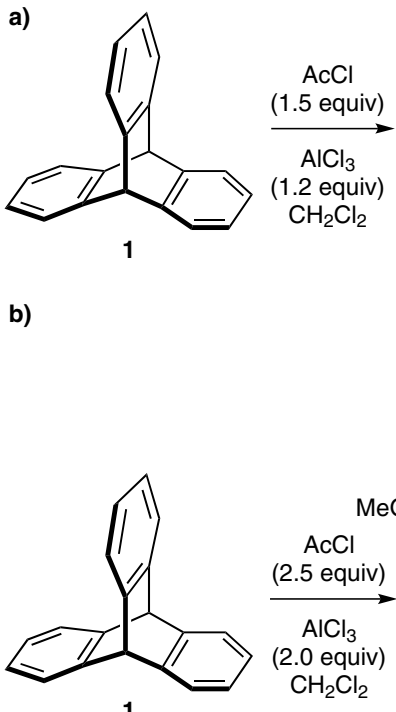

$\mathrm{CH}_{2} \mathrm{Cl}_{2}$

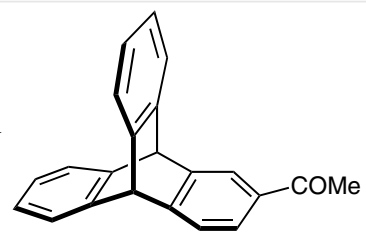

$18(84 \%)$

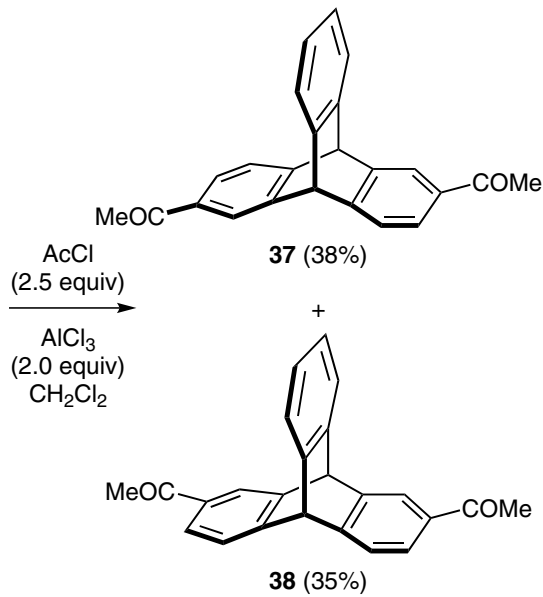

c)

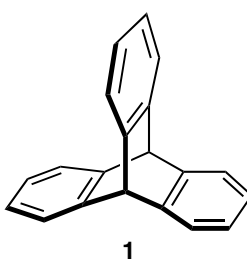

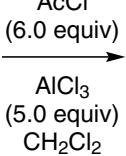

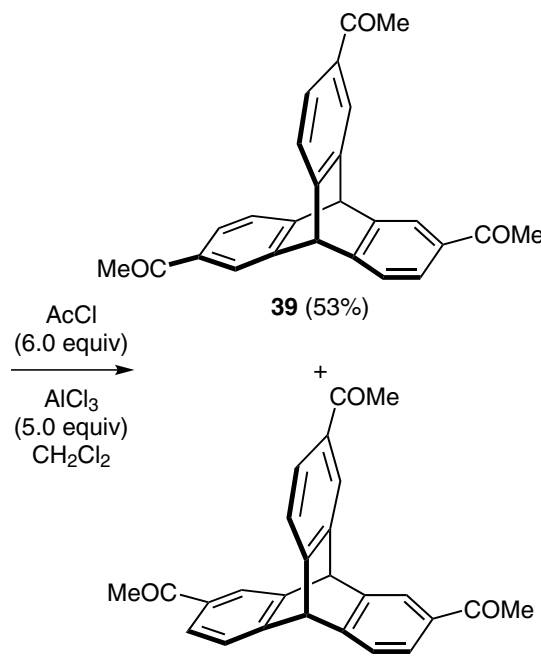

$40(17 \%)$

Scheme 14 Selective acetylation of triptycene (1)

Similar to formyl-substituted triptycenes, we also studied further transformations of the acetyl-substituted triptycenes. It was found that acetyl-substituted triptycenes $\mathbf{1 8}$ and 37-40 could be converted into the corresponding acetoxytriptycenes 41-45 in high yields via Baeyer-Villiger oxidation with $m$-chloroperoxybenzoic acid (MCPBA) (2 mmol per acetyl group) at room temperature (Scheme 15). The acetyl group(s) in these acetoxytriptycenes could also be easily removed to produce hydroxy-substituted triptycenes. $^{26}$

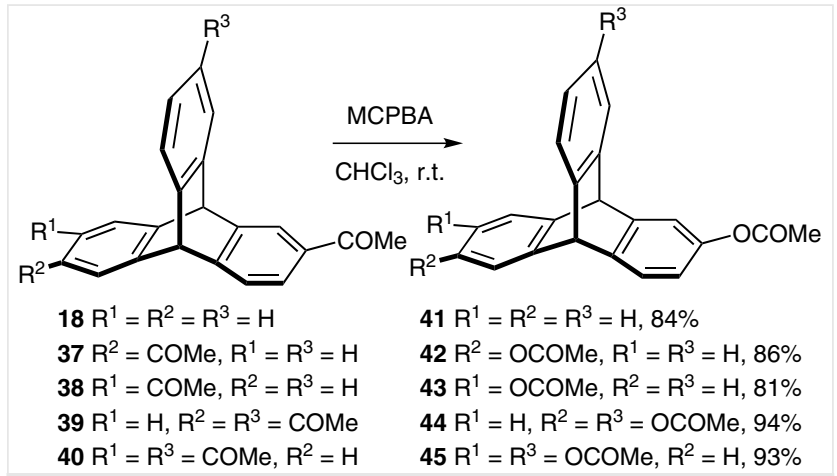

Scheme 15 Baeyer-Villiger oxidations of acetyl-substituted triptycenes

Treatment of acetyl-substituted triptycenes 18 and 3740 with hydroxylamine hydrochloride and sodium acetate trihydrate gave the corresponding acetyl-oxime triptycenes 46-50 in 72-98\% yields. Next, in the presence of a catalytic amount of mercury(II) chloride $\left(\mathrm{HgCl}_{2}\right)$ in acetonitrile, acetyl-oxime triptycenes $\mathbf{4 6 - 5 0}$ could be transformed into acetamino-substituted triptycenes 51-55 in yields of 76-90\% through Beckmann rearrangement, as shown in Scheme 16a. In addition, 2,7,14-triacetaminotriptycene (55) was treated with sodium hydroxide in ethanol-water solution to produce 2,7,14-triaminotriptycene (56) in a very high yield of $96 \%$ (Scheme 16b).

\subsubsection{Nitration}

The nitro group is a very useful functional moiety in organic synthesis, which can be transformed into various other groups, such as halo, cyano, hydroxy, etc., via nucleophilic displacement. Moreover, it is difficult to generate triptycenes substituted with nitro group(s) via the direct DielsAlder reaction strategy, thus, nitration of unsubstituted triptycene (1) has become the dominant method for introducing a nitro group to the triptycene skeleton.

In 1969, Klanderm and Perkins ${ }^{27}$ were the first to prepare a nitro-substituted derivative of triptycene (1). When triptycene (1) was treated with concentrated nitric acid in glacial acetic acid at $27-29{ }^{\circ} \mathrm{C}$ for three hours, 2-nitrotriptycene (57) was obtained as the major product in $44 \%$ yield, along with dinitrotriptycene and a trace amount of 1-nitrotriptycene. As with acylation, nitration of triptycene also preferred to occur at the $\beta$-position of the benzene ring. Shigeru and Ryusei ${ }^{28}$ subsequently found that treatment of triptycene (1) with three equivalents of acetyl nitrate solution in glacial acetic acid, in the presence of acetic anhy- 
a)
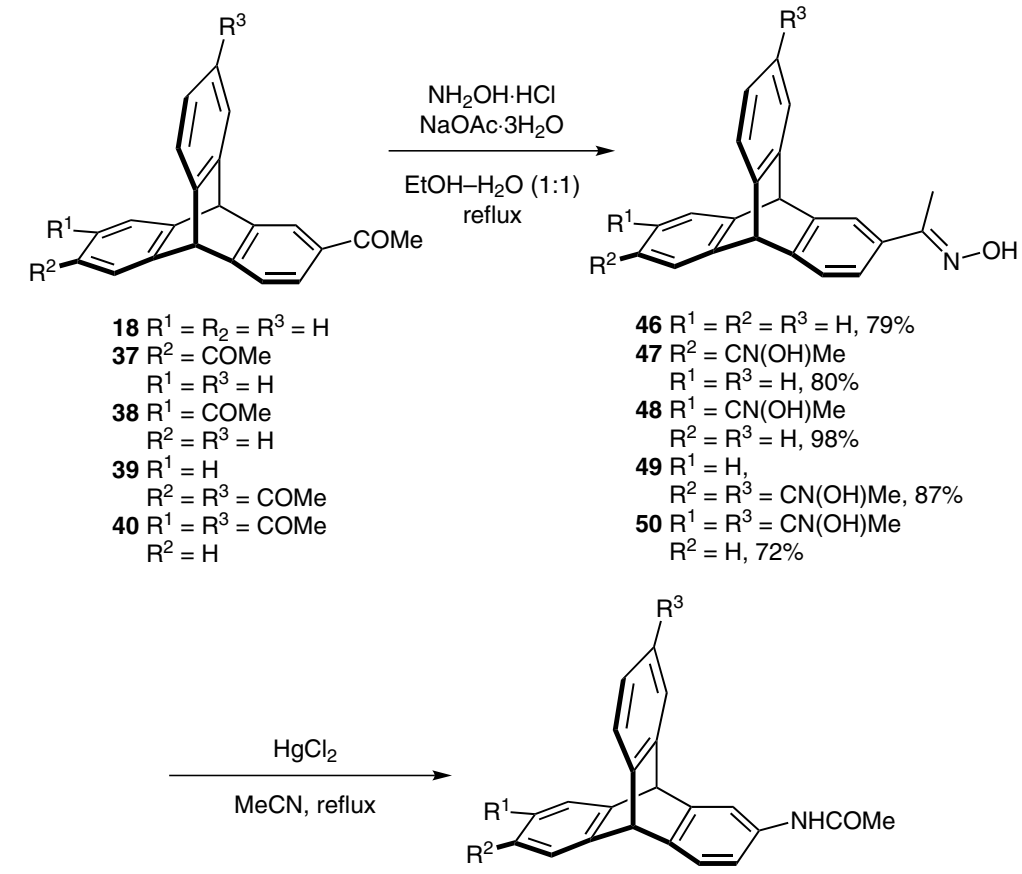

$51 R^{1}=R^{2}=R^{3}=H, 86 \%$

$52 R^{2}=$ NHCOMe, $R^{1}=R^{3}=H, 88 \%$

$53 \mathrm{R}^{1}=\mathrm{NHCOMe}, \mathrm{R}^{2}=\mathrm{R}^{3}=\mathrm{H}, 76 \%$

$54 R^{1}=H, R^{2}=R^{3}=$ NHCOMe, $78 \%$

$55 R^{1}=R^{3}=$ NHCOMe, $R^{2}=H, 90 \%$

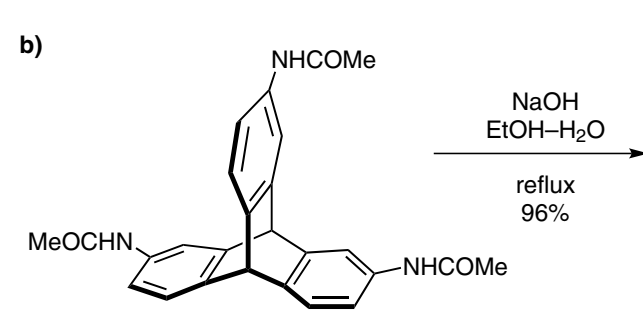

55

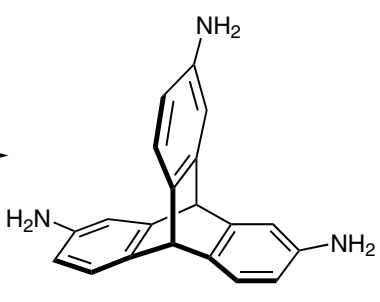

56

Scheme 16 Synthesis and further transformations of acetyl-oxime triptycenes

dride at $0{ }^{\circ} \mathrm{C}$ for two hours, gave a mixture of nitrated triptycenes, which included mononitro-, dinitro- and a small amount of trinitro- (2,6,14- and 2,7,14-) products 57-61 (Scheme 17). It is noteworthy that a nitro group was substituted on one ring of triptycene, and then further nitro substitution occurred at the $\beta$-positions of the other two rings, which resulted in a mixture of products. This result showed that the $\beta$-positions were the most reactive sites toward electrophilic aromatic substitution in triptycene, which is consistent with the theory of the fused-ortho effect. ${ }^{29}$

Realistically, it is more significant to achieve a specific product, rather than a mixture, via the nitration of triptycene. Thus, Chong and MacLachlan ${ }^{30}$ attempted to improve the conditions of the nitration reaction in order to obtain a single nitrated triptycene as the sole product. After a number of attempts, they found that both the reaction time and the amount of nitrating agent were important to control the nitration process. As mentioned before, the $\beta$-positions of triptycene are the most reactive sites toward electrophilic aromatic substitution; the introduction of a nitro group to one phenyl ring does not deactivate the $\beta$-positions of the other two rings, which results in further nitration to afford a mixture of products. 


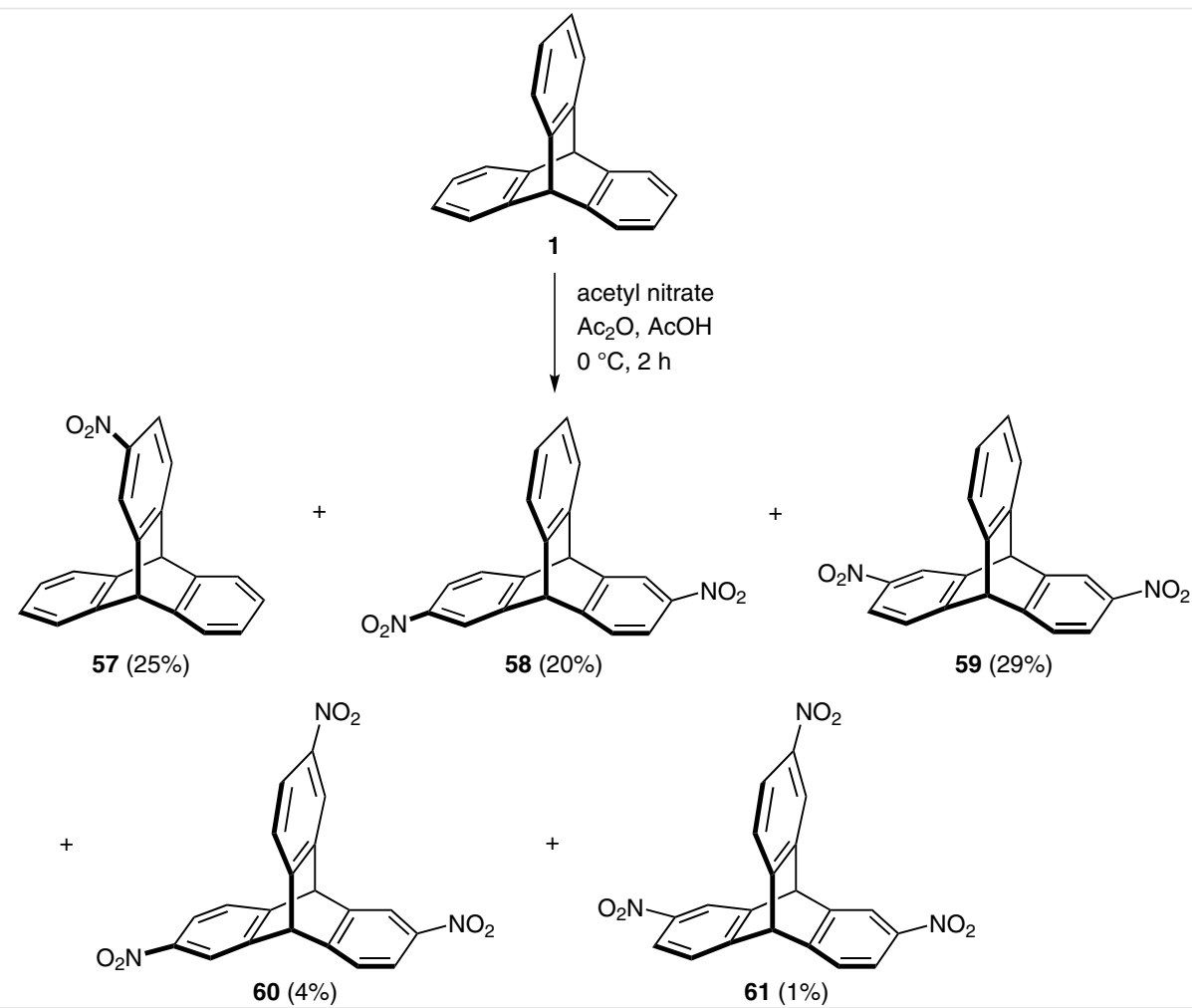

Scheme 17 Nitration of triptycene (1) with acetyl nitrate

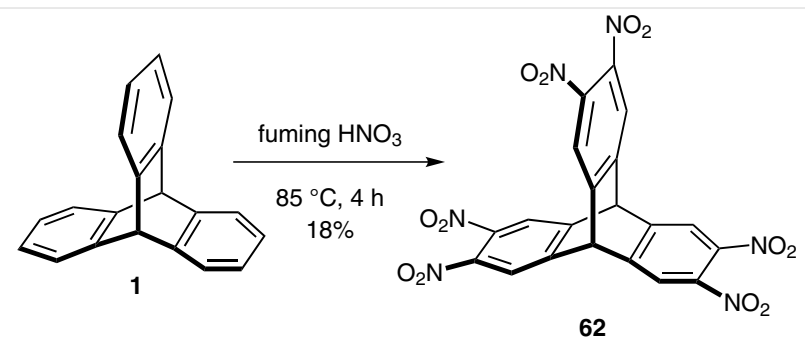

Scheme 18 Nitration of triptycene (1) with fuming nitric acid

Moreover, the use of an increased amount of potassium nitrate $\left(\mathrm{KNO}_{3}\right)$ would increase the yield of dinitrotriptycene. Thus, the most desirable method for the mono-nitration of triptycene was to use a stoichiometric quantity of $\mathrm{KNO}_{3}$ in acetic acid under heating for a relatively short reaction time. In fact, it was found that the mono-nitration of triptycene was almost complete in six hours with a yield of about $70 \%$.

With a sufficient amount of concentrated nitric acid, the nitration of triptycene would proceed to afford a pair of triple nitration isomers, 2,6,14-trinitrotriptycene (60) and 2,7,14-trinitrotriptycene (61) in an approximate ratio of 3:1 (according to statistics), which indicates that the site of nitration had little relation with the electronic effects. Soon after, we found that a prolonged reaction time and an in- creased temperature had positive effects on the nitration of triptycene. ${ }^{31}$ Consequently, triptycene (1) was heated to $75{ }^{\circ} \mathrm{C}$ in concentrated $\mathrm{HNO}_{3}$, and then kept stirring for 24 hours; the yield of 2,6,14-trinitrotriptycene $(\mathbf{6 0})$ was found to range from the $33 \%$ reported by MacLachlan ${ }^{30 a}$ to $64 \%$, while another triple nitration product, 2,7,14-trinitrotriptycene (61) was isolated in $21 \%$ yield as well. Allowing the reaction temperature to continue rising to reflux resulted in the isolation of 2,6,14-trinitrotriptycene $(\mathbf{6 0})$ in an increased yield of up to $81 \%{ }^{32}$ Compared with mono- and trinitrotriptycenes, the preparation of dinitrotriptycenes as the sole products under appropriate nitration condition still needs to be achieved. At present, the isolation of dinitrotriptycenes can only be accomplished by separation through solvent treatment or column chromatography of a mixture of nitration products. ${ }^{33}$ Recently, Mastalerz and coworkers $^{34}$ reported that treatment of triptycene (1) with fuming nitric acid and heating at $80-85^{\circ} \mathrm{C}$ for four hours gave the further nitration product, 2,3,6,7,13,14-hexanitrotriptycene (62) in a yield of $18 \%$ (Scheme 18 ).

On treatment with Raney nickel in the presence of hydrazine, 2-nitrotriptycene, dinitrotriptycenes and trinitrotriptycenes could all be easily reduced into the corresponding aminotriptycenes, in almost quantitative yields. It was also found that 2-aminotriptycene $(\mathbf{6 3})$ could be trans- 

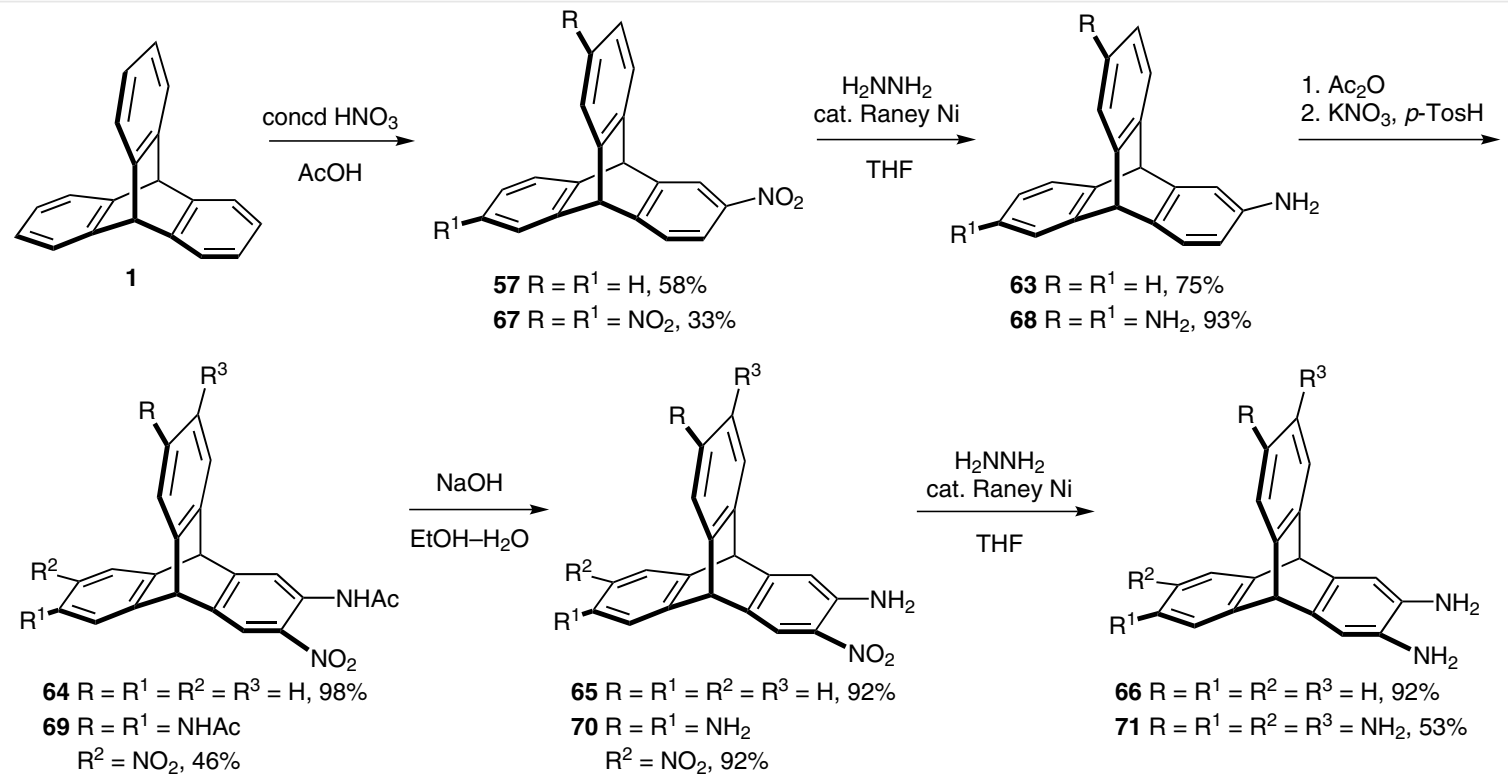

Scheme 19 Synthesis of polyaminotriptycenes

formed in situ into 2-acetamidotriptycene, which was then treated with stoichiometric nitric acid at low temperature to produce the nitration product, 2-acetamido-3-nitrotriptycene (64), selectively. ${ }^{30}$ Subsequent hydrolysis of $\mathbf{6 4}$ and reduction of the corresponding amine $\mathbf{6 5}$ resulted in the formation of 2,3-diaminotriptycene (66) in an overall yield of more than $80 \%$ based on 2-aminotriptycene (63). Using the same strategy, 2,3,6,7,14,15-hexaaminotriptycene (71) could be obtained by the sequential nitration and reduction of trinitrotriptycene $\mathbf{7 0}$ (Scheme 19).

Polyaminotriptycenes, especially 2,3,6,7,14,15-hexaaminotriptycene (71), are air-sensitive, which creates issues with their storage. In 2011, Mastalerz and co-workers $^{34}$ developed a convenient synthetic route to hexaammoniumtriptycene hexachloride (72), an air-stable salt of hexaminotriptycene 71. As shown in scheme 20, 2,3,6,7,13,14-hexanitrotriptycene (62) was subjected to reduction using tin(II) chloride dihydrate $\left(\mathrm{SnCl}_{2} \cdot 2 \mathrm{H}_{2} \mathrm{O}\right)$ in aqueous hydrochloric acid/ethanol solution to give ammonium salt 72, as a pale yellow solid in quantitative yield.

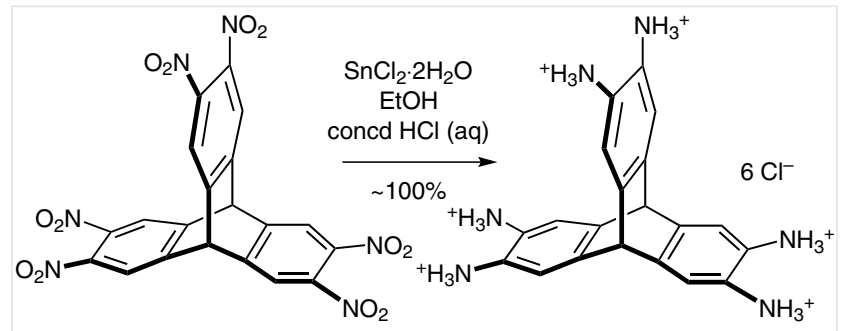

62

72

Scheme 20 Synthesis of hexaammoniumtriptycene hexachloride (72)
Furthermore, the amino group can be conveniently transformed into other functional groups. As shown in Scheme 21, 2,6-diaminotriptycene (73) was dissolved in aqueous hydrogen bromide ( $\mathrm{HBr})$ solution, and then treated with sodium nitrite $\left(\mathrm{NaNO}_{2}\right)$ and copper(I) bromide $(\mathrm{CuBr})$ to give 2,6-dibromotriptycene (74) in 51\% yield. ${ }^{33}$ Similarly, 2,6-diiodotritpycene (75) could be synthesized in 54\% yield by a Sandmeyer reaction in the presence of potassium iodide (KI). The dihalotriptycenes were further applied to prepare a novel aromatic polymer, poly(2,6-triptycene), via a nickel(0)-mediated Yamamoto-type polycondensationhomopolymerization. This polymer showed excellent solubility in common organic solvents along with good thermal stability.

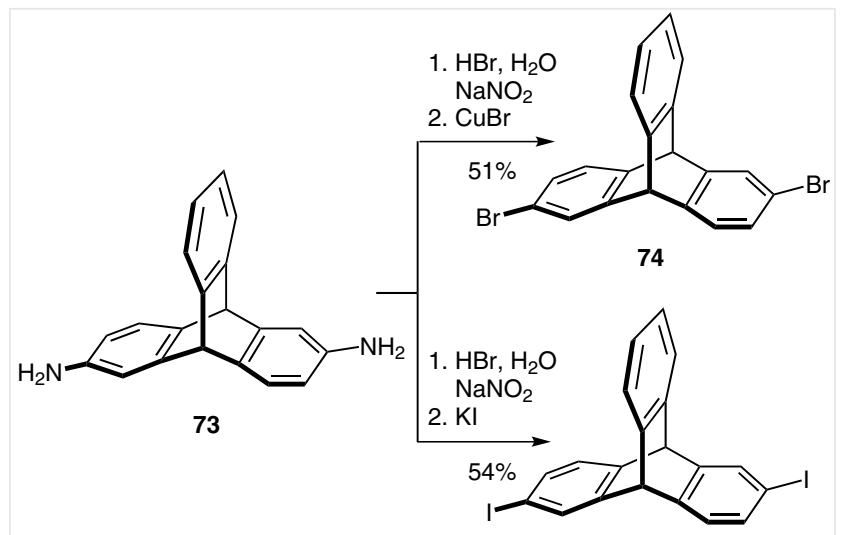

75

Scheme 21 Sandmeyer reactions of 2,6-diaminotriptycene (73) 
Under similar Sandmeyer reaction conditions, the corresponding tribromotriptycenes and triiodotriptycenes could also be obtained in high yields starting from the trinitrotriptycenes. Moreover, triaminotriptycenes $\mathbf{6 0}$ and $\mathbf{6 1}$ on treatment with concentrated sulfuric acid in an aqueous solution of sodium nitrite gave the corresponding trihydroxytriptycenes $\mathbf{7 6}$ and $\mathbf{7 7}$ in 75 and 81\% yields, respectively (Scheme 22).

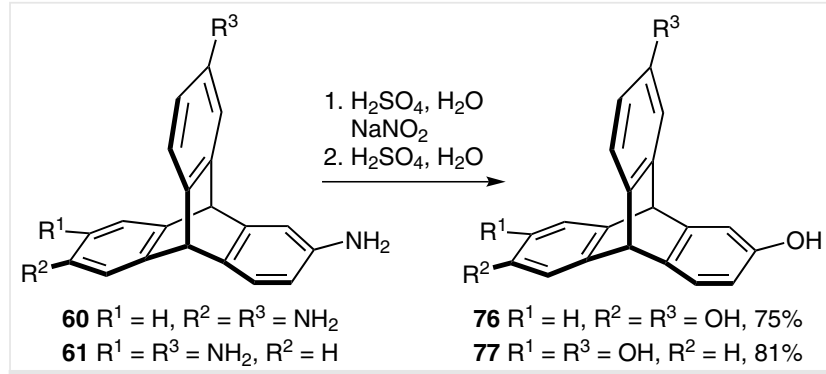

Scheme 22 Synthesis of trihydroxytriptycenes

\subsubsection{Halogenation}

Halo groups such as fluoro, chloro, bromo and iodo are particularly important in organic synthesis. They can be transformed into many other functional groups and also participate as good leaving groups in a wide variety of homo- and cross-coupling reactions. Although halogenated triptycenes can easily be obtained by the Diels-Alder reaction approach, the comparatively low yields and difficulties associated with their purification and separation still limit their preparation. Thus, the direct introduction of a halo group to the triptycene skeleton provides another opportunity for the synthesis of halogenated triptycenes.

In 1971, Ballester and co-workers ${ }^{35}$ reported the chlorination of triptycene using the powerful chlorinating reagent, BMC (Ballester-Molinet-Castaner reagent). ${ }^{36}$ As shown in Scheme 23, triptycene (1) was treated with sulfur monochloride $\left(\mathrm{S}_{2} \mathrm{Cl}_{2}\right)$ in the presence of a boiling solution of anhydrous aluminum chloride in freshly distilled sulfuryl chloride $\left(\mathrm{SO}_{2} \mathrm{Cl}_{2}\right)$ to afford the perchlorination product, dodecachlorotriptycene $\mathbf{7 8}$, in a good $88 \%$ yield.

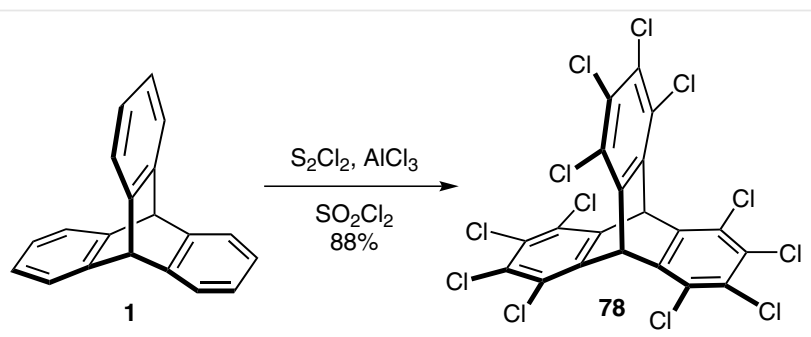

Scheme 23 Perchlorination of triptycene (1)
Later, Zupan and Šket ${ }^{37}$ made use of xenon difluoride $\left(\mathrm{XeF}_{2}\right)$ in the presence of hydrogen fluoride (HF) to achieve the selective fluorination of triptycene (1). As shown in Scheme 24, treatment of triptycene (1) with one equivalent of xenon difluoride, in dichloromethane at room temperature in the presence of a catalytic amount of hydrogen fluoride, provided two fluorination products, 2-fluorotriptycene (79) and 1-fluorotriptycene (80). As expected, the fluorination also preferred to occur at the $\beta$-position of the benzene ring to afford 2-fluorotriptycene as the major product.

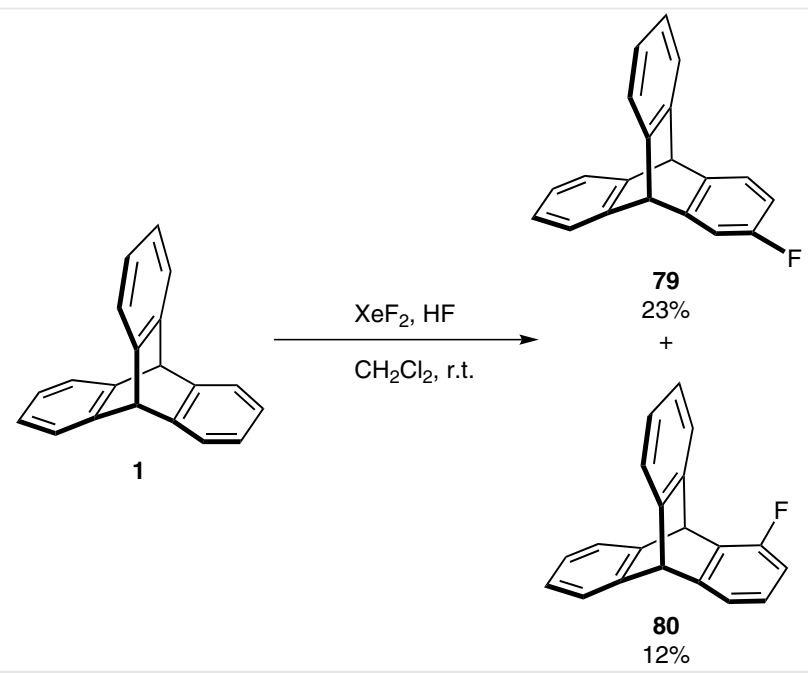

Scheme 24 Fluorination of triptycene (1)

King and co-workers ${ }^{38}$ improved the earlier reported method by Skvarchenko and co-workers ${ }^{39}$ for the bromination of triptycene (1). Consequently, triptycene (1) was dissolved in chloroform and stirred in the presence of iron filings at $25^{\circ} \mathrm{C}$. The mixture was then treated with bromine for one hour to afford hexabromotriptycene $\mathbf{8 1}$ in $64 \%$ yield (Scheme 25).

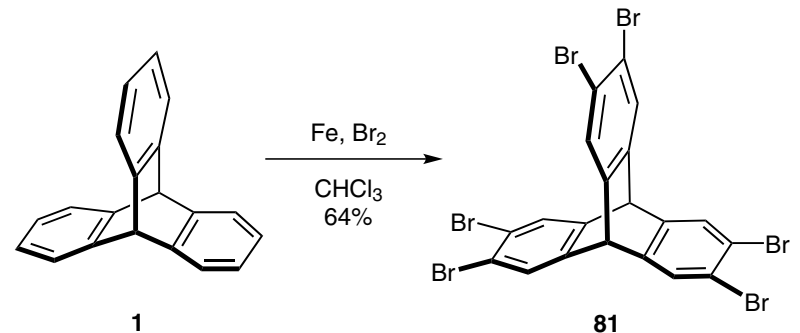

Scheme 25 Bromination of triptycene (1) 
a)

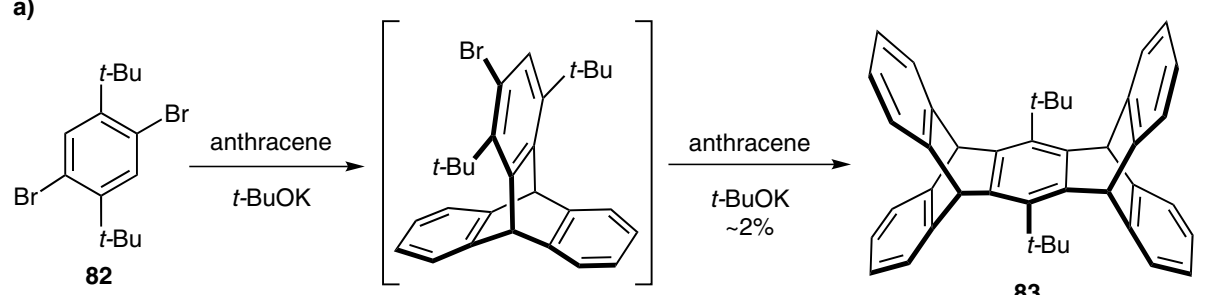

83<smiles>[R]c1c(Br)c(Br)c([R])c(Br)c1Br</smiles>

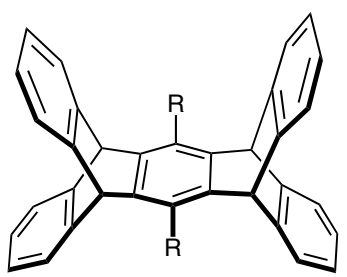

$85 \mathrm{a}=\mathrm{Me}, 14 \%$

85b $\mathrm{R}=\mathrm{OMe}, 36 \%$

c)

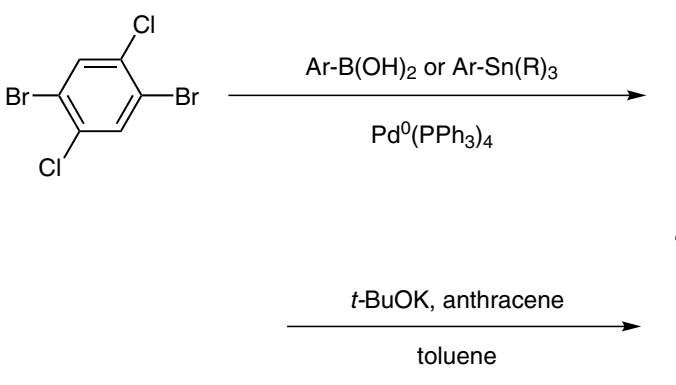<smiles>Clc1cc(Br)c(Br)cc1Cl</smiles>
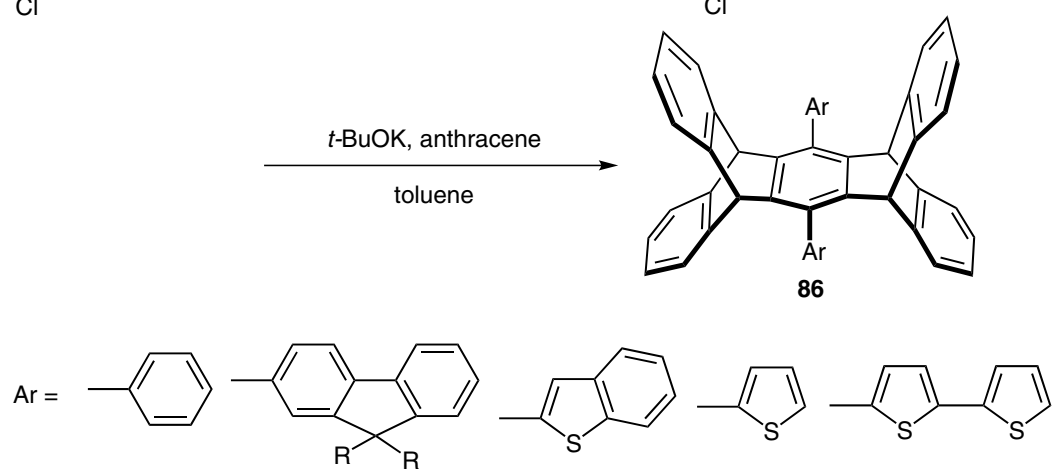

a: $19 \%$

b: $21 \%$

$\mathrm{R}=$ 2-ethylhexyl

c: $34 \%$

d: $56 \%$

e: $27 \%$

Scheme 26 Synthesis of substituted pentiptycenes

\section{Synthesis of Substituted Pentiptycenes}

In comparison with triptycene, pentiptycene has five phenyl rings, and thus contains more reactive positions than triptycene. However, investigations on the reactions of pentiptycene have almost always been focused on the functionalization of the central ring of para-pentiptycene.

Diels-Alder addition reactions of anthracene with the appropriate arynes, formed in situ from various halogenated benzenes, gave the corresponding substituted pentiptycenes. Consequently, Cadogan and co-workers ${ }^{12}$ synthesized di-tert-butylpentiptycene $\mathbf{8 3}$ by the reaction between the aryne formed from 1,4-dibromo-2,5-di-tert-butylbenzene (82) and anthracene in the presence of a strong base (Scheme 26a). The extremely low yield obtained was of no practical use from a synthetic point-of-view. Ten years later, Hart and co-workers ${ }^{40}$ utilized tetrabromo-p-xylene (84,
$\mathrm{R}=\mathrm{Me})$ and 1,2,4,5-tetrabromo-3,6-dimethoxybenzene $(\mathbf{8 4}, \mathrm{R}=\mathrm{OMe})$ to generate benzyne intermediates with $n$ butyllithium. This method improved the yield of the DielsAlder addition reaction to a certain extent, the corresponding substituted pentiptycenes $\mathbf{8 5} \mathbf{a}, \mathbf{b}$ being obtained in reasonable yields (Scheme 26b). Using a similar synthetic strategy, Anzenbacher and co-workers ${ }^{13}$ synthesized a series of diaryl pentiptycenes $\mathbf{8 6 a}-\mathbf{e}$ in moderate yields by the potassium tert-butoxide promoted double dehydrohalogenations/cycloadditions of 1,4-diaryl-2,5-dichlorobenzenes with anthracene (Scheme 26c). The consumption of excess anthracene and the poor yields limit the scope of its application to a certain degree, thus this synthetic strategy toward substituted pentiptycenes remains to be improved.

Compared with pentiptycene, pentiptycene quinone $\mathbf{8 7}$ can be prepared easily from the inexpensive precursors, benzoquinone and anthracene. With thorough improve- 


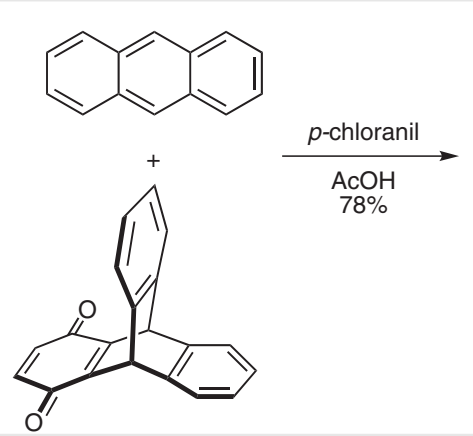

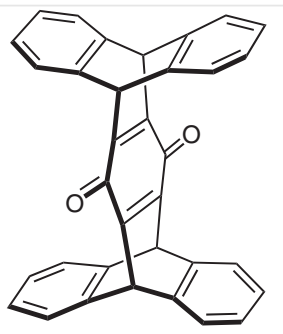

87

Scheme $\mathbf{2 7}$ Two routes for the synthesis of pentiptycene quinone $\mathbf{8 7}$

ment and optimization studies, ${ }^{7 \mathrm{a}, \mathrm{b}, 41}$ we have developed a practical and efficient method ${ }^{42}$ for the synthesis of pentiptycene quinone 87. As shown in Scheme 27, pentiptycene $\mathbf{8 7}$ was obtained in $78 \%$ yield by the reaction of anthracene with one equivalent of triptycene quinone in acetic acid in the presence of $p$-chloranil, which served as the oxidant instead of the excess of triptycene quinone, thereby decreasing the unnecessary consumption of triptycene quinone. It was also found that 87 could be synthesized in $89 \%$ yield via a one-pot Diels-Alder addition of two equivalents of anthracene with one equivalent of $p$-benzoquinone in acetic acid at reflux temperature in the presence of $p$-chloranil (Scheme 27).

Starting from the readily available pentiptycene quinone 87, Swager, Yang and co-workers ${ }^{7 a, b, 41 c, 43}$ attempted to obtain various central-ring substituted pentiptycene derivatives. As shown in Scheme 28, nucleophilic addition of lithium trimethylsilylacetylide to pentiptycene quinone $\mathbf{8 7}$, followed by reductive aromatization gave the trimethylsilyl-protected diethynylpentiptycene $\mathbf{8 8} .^{\text {7a,b }}$ This reaction represents the first example in which pentiptycene quinone $\mathbf{8 7}$ acts as a precursor for central-ring disubstituted pentiptycenes.

In 2006, Yang and $\mathrm{Ko}^{43 \mathrm{a}}$ carried out the reaction between pentiptycene quinone $\mathbf{8 7}$ and hydroxylamine in THF in the presence of hydrochloric acid. Surprisingly, it was found that monooxime $\mathbf{8 9}$ rather than the dioxime was obtained, even when a large excess of hydroxylamine or prolonged reaction times were employed. Monooxime $\mathbf{8 9}$ could be further converted into aminophenol 90 by subsequent reduction using stannous chloride in dichloromethane (Scheme 29). Aminophenol $\mathbf{9 0}$ is an important precursor for Sandmeyer reactions, which makes it potentially promising for the synthesis of central-ring unsymmetrically disubstituted pentiptycenes. As shown in Scheme 29, the amino group in 90 could be removed to form pentiptycene phenol 91 by simple treatment with phosphinic acid $\left(\mathrm{H}_{3} \mathrm{PO}_{2}\right)$ andtert-butyl nitrite. Meanwhile, the amino group in $\mathbf{9 0}$ could be converted into a nitro group under slightly different reaction conditions to afford compound $\mathbf{9 2}$.

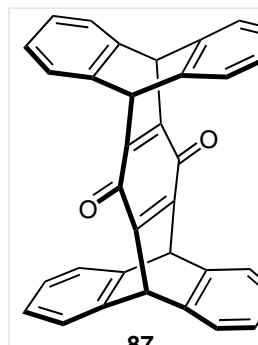

87<smiles>c1ccc2cc3ccccc3cc2c1</smiles>

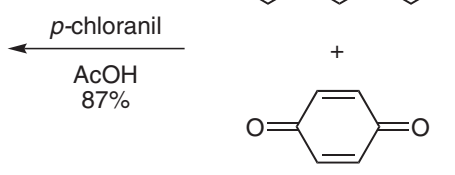
conditions in ethanol (Scheme 30) to give iodide 94. As iodopentiptycene 94 possesses a good leaving group, it was successfully used as a building block for the synthesis of extended $\pi$-conjugated pentiptycenes under Sonogashira, Heck and Suzuki coupling reaction conditions. Using the common bromination agent, $\mathrm{N}$-bromosuccinimide (NBS), alkoxy-substituted pentiptycene $\mathbf{9 3}$ could also be functionalized with a bromine group at the position para to the alkoxy group, to afford bromopentiptycene $\mathbf{9 5}$ in $90 \%$ yield. Moreover, the bromo group in $\mathbf{9 5}$ was easily converted into cyano and formyl moieties, which provided additional unsymmetrical pentiptycene building blocks 96 and 97 for further applications (Scheme 30). 


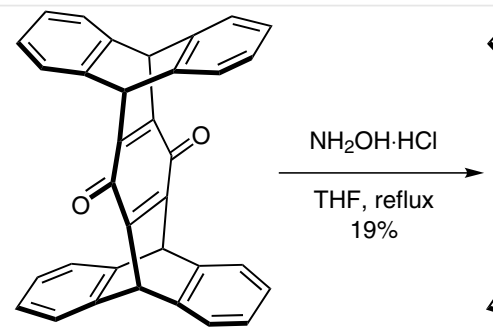

87

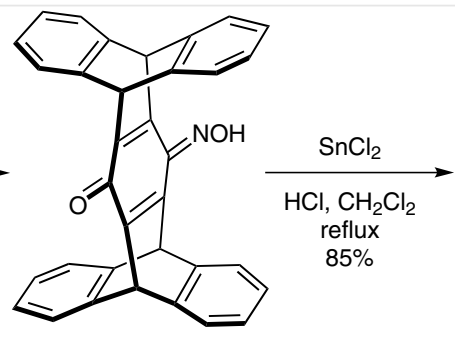

89

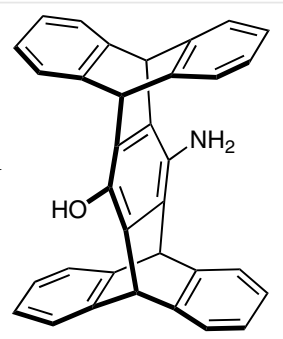

90

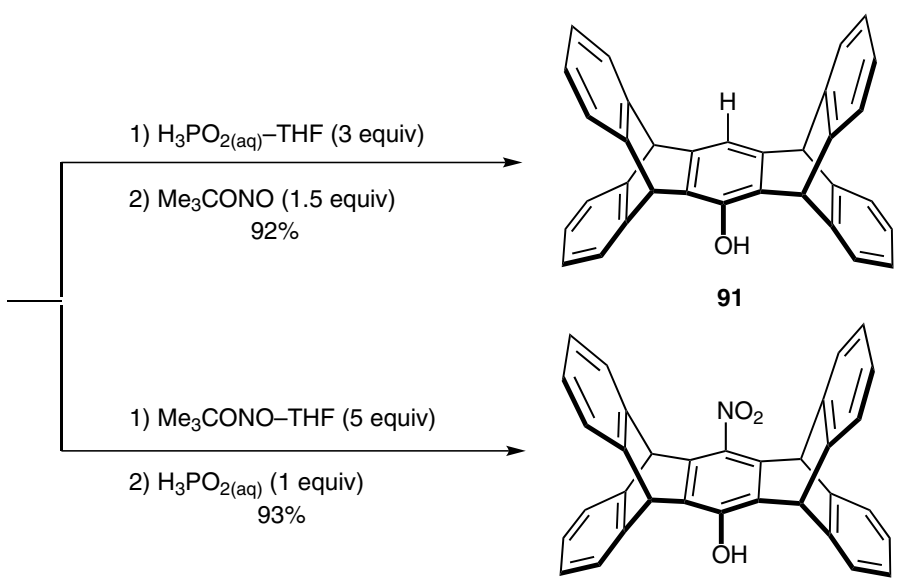

92

Scheme 29 Synthesis of central-ring unsymmetrically disubstituted pentiptycenes

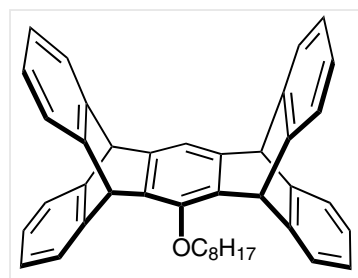

93

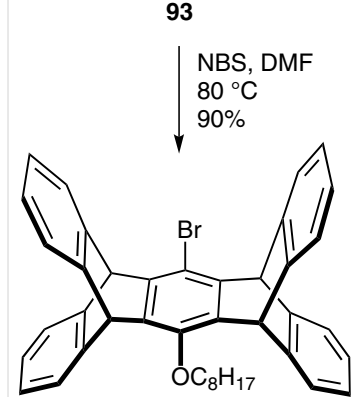

95

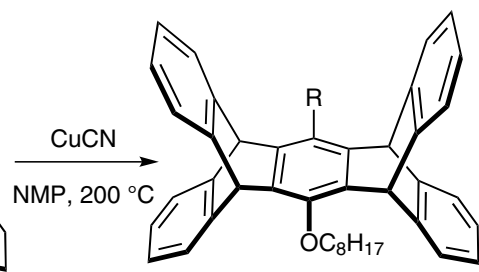

$$
\begin{gathered}
96 \mathrm{R}=\mathrm{CN} \\
87 \% \\
\begin{array}{c}
97 \mathrm{R}=\mathrm{CHO} \\
90 \%
\end{array}
\end{gathered}
$$

Scheme 30 Halogenation of alkoxy-substituted pentiptycene 93

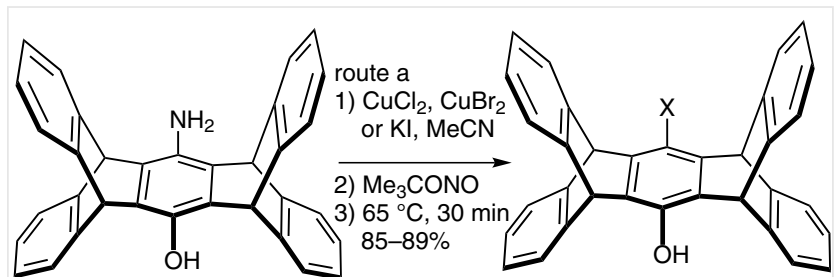

$98 \mathrm{X}=\mathrm{Cl}, \mathrm{Br}$,

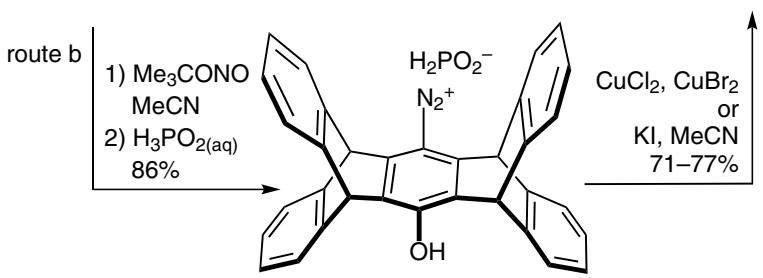

Scheme 31 Halogenation of unsymmetrical aminopentiptycene phenol 90

Under deamination-halogenation conditions, the center-ring halogenated pentiptycene phenols 98 could be obtained in good yields in either a one-pot fashion (Scheme 31 , route a), or via a two-step method (Scheme 31, route b), starting from unsymmetrical aminopentiptycene phenol 
90, which proceeded via the formation of a diazonium salt intermediate. In these reactions, tert-butyl nitrite acted as the diazotizing agent, while copper(II) chloride $\left(\mathrm{CuCl}_{2}\right)$, copper(II) bromide $\left(\mathrm{CuBr}_{2}\right)$ or KI was the halogen source. These halogenated pentiptycene phenols $\mathbf{9 8}$ could be employed as useful substrates for palladium-catalyzed Heck, Suzuki, or Sonogashira coupling reactions to afford the corresponding $\pi$-conjugated pentiptycene systems.

As shown in Scheme 32, nitropentiptycene $\mathbf{1 0 0}$ was synthesized from nitropentiptycene phenol 92 via a palladium-catalyzed reduction of a triflate group. It is worth noting that to obtain a reasonable yield of the reduction product required the use of the more reactive palladium cata- lyst, tetrakis(triphenylphosphine)palladium(0) $\left[\mathrm{Pd}\left(\mathrm{PPh}_{3}\right)_{4}\right]$, while the aryl triflate (e.g. 99) had to contain an electronwithdrawing substituent. Next, reduction of the nitro group in 100 afforded pentiptycene aniline 101, which could be further converted into pentiptycene dihalides 102-104.

Nucleophilic aromatic substitution $\left(\mathrm{S}_{\mathrm{N}} \mathrm{Ar}\right)$ can be used as an alternative and efficient route to synthesize pentiptycene halides. As shown in Scheme 33, halopentiptycenes 105 and 106 were obtained by the $S_{N} A r$ reaction of pentiptycene triflate 99 with lithium bromide ( $\mathrm{LiBr}$ ) and lithium iodide (LiI) in DMF, as a result of $\mathrm{C}-\mathrm{O}$ bond cleavage of the triflate group. Compared with the transformation from pentiptycene triflate 99 into pentiptycene dihalides 102-

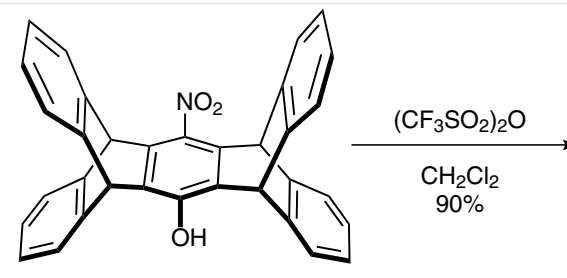

92

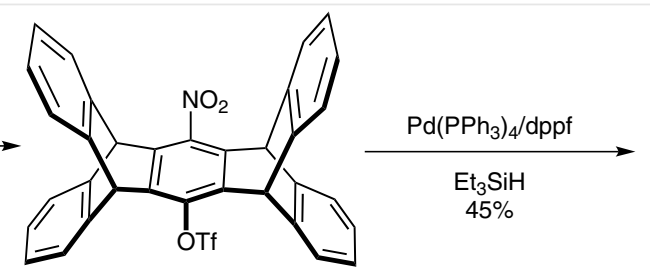

99

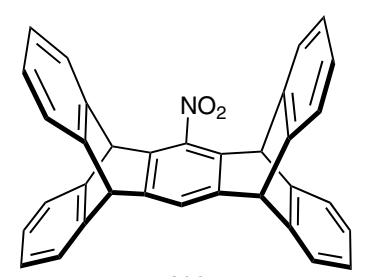

100

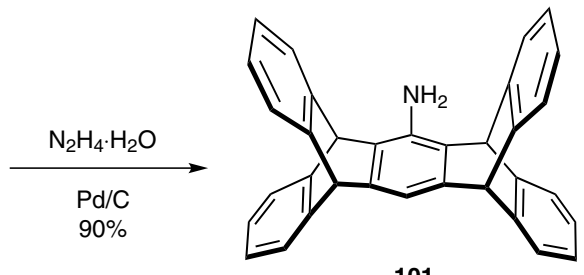

101
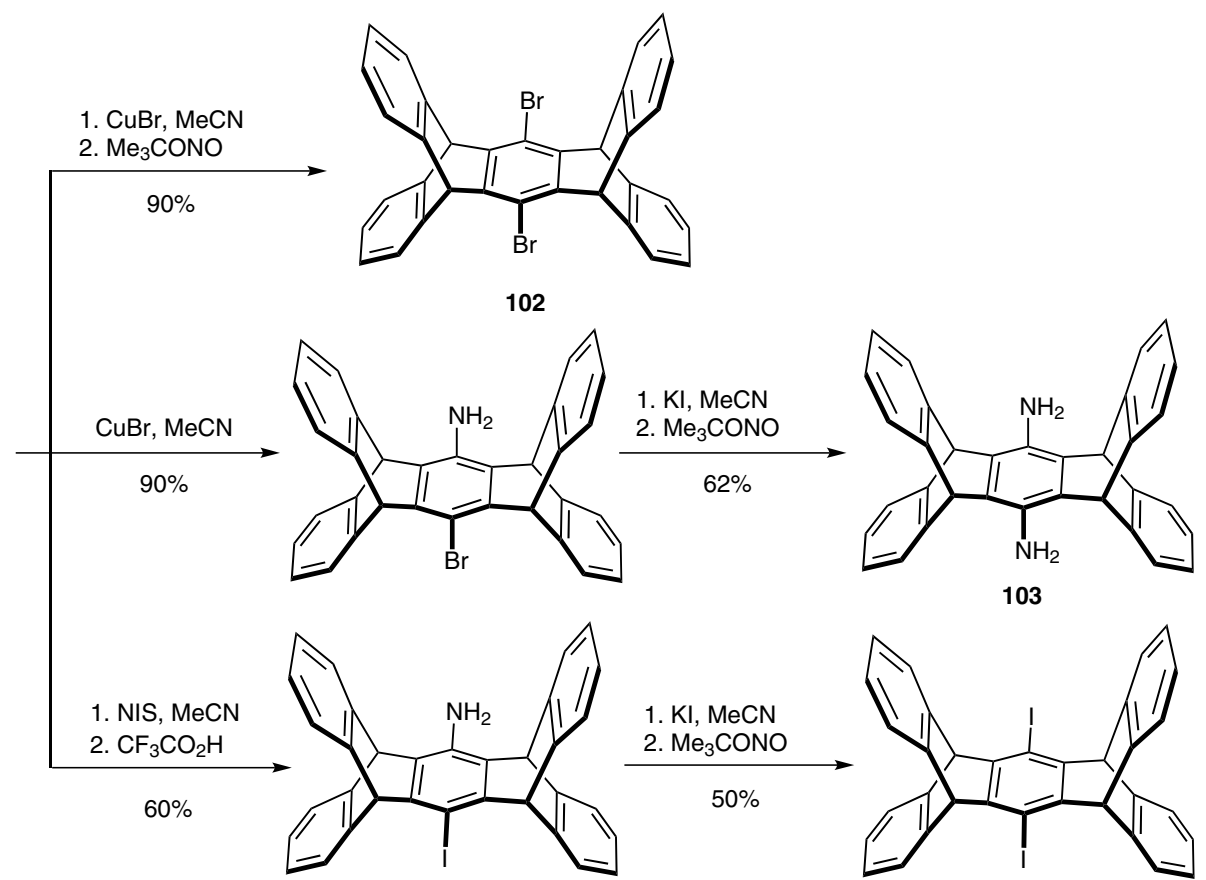

103

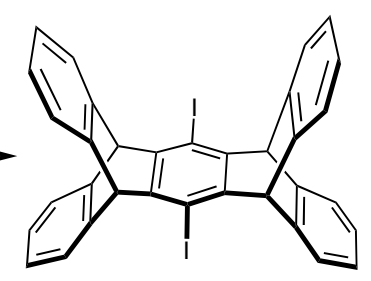

104

Scheme 32 Synthesis of pentiptycene dihalides 

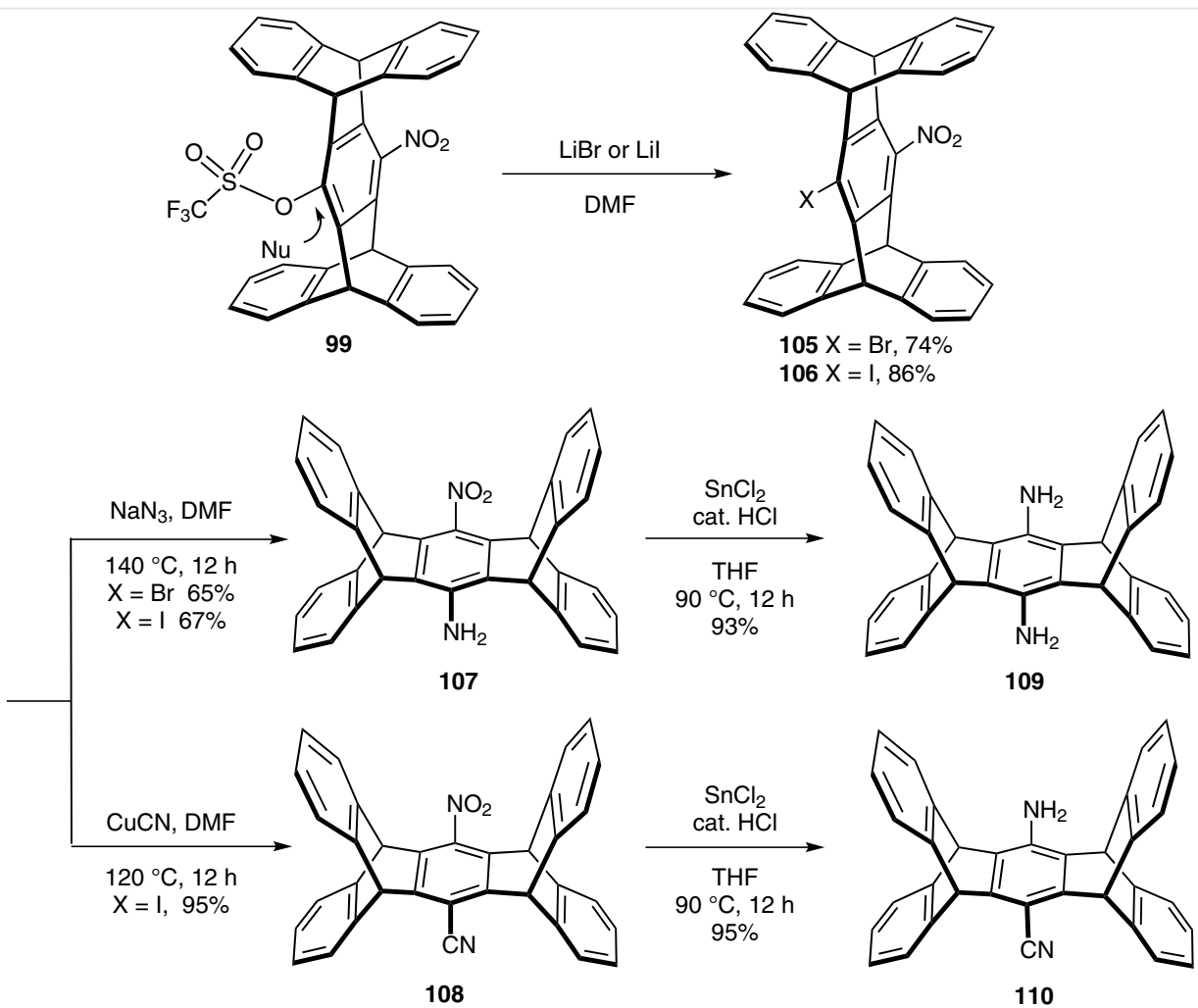

Scheme 33 Nucleophilic aromatic substitution $\left(S_{N} A r\right)$ reactions of pentiptycene triflate 99

104, this method could not only be carried out on a largescale synthesis of the pentiptycene, but also provided an easy access to new pentiptycene building blocks containing nitro, amino and cyano substituents (107-110).

In contrast with the central-ring functionalized pentiptycenes, few peripheral-functionalized pentiptycene derivatives have been reported to date. However, peripheralfunctionalized pentiptycenes can make full use of all the regions of the pentiptycene, including two triptycene-like Vshaped open electron-rich cavities, and another two big flat-bottomed boat-shaped open electron-rich cavities. In addition, they represent new useful building blocks, and consequently have found wide applications in supramolecular chemistry and materials science. Thus, we have developed a practical and efficient method to synthesize a series of peripheral methoxy-substituted pentiptycene quinones. ${ }^{42,44}$ The Diels-Alder addition reaction between $p$ triptycene quinone and methoxyanthracene in acetic acid and 1,2-dichloroethane, in the presence of $p$-chloranil, afforded the corresponding peripheral methoxy-substituted pentiptycene quinones 111-117 (Figure 2) in high yields. On the basis of further studies, we found that some pentiptycene quinones with $C_{2 v}$ or $D_{2 h}$ symmetry, such as tetramethoxypentiptycene quinone isomers 115 and 116 and octamethoxypentiptycene quinone $\mathbf{1 1 7}$, could be obtained in higher yields via one-pot reactions between one equivalent of the $p$-benzoquinone and two equivalents of anthracene in acetic acid, in the presence of two equivalents of $p$-chloranil.

Moreover, we also found that dimethoxy-substituted pentiptycene $\mathbf{1 1 4}$ could be easily transformed into the corresponding pentiptycene 0 -quinone 118 in $94 \%$ yield by the treatment with three equivalents of cerium ammonium nitrate (CAN) in aqueous acetonitrile (Scheme 34a).

Under the same reaction conditions, the pentiptycene bis(o-quinone)s 119 and 120 were obtained by the oxidation of tetramethoxypentiptycene quinone isomers 115 and 116, respectively (Scheme 34b). However, we additionally found that the two 0 -dimethoxybenzene moieties situated on the same side of the pentiptycene quinones could not be oxidized completely, even on treatment of the substrate with a large excess of CAN over a longer reaction time in aqueous acetonitrile. As shown in Scheme 34c, treatment of dimethoxypentiptycene quinone $\mathbf{1 2 1}$ with six equivalents of CAN gave compound 122 in $80 \%$ yield, instead of pentiptycene bis(o-quinone). Similar to the case of 121, only two of the four $\boldsymbol{0}$-dimethoxybenzene moieties in pentiptycene quinone 117 could be oxidized by CAN to give the two isomeric products 123 and 124 in a total yield of 80\% (Scheme 34d). These peripheral-functionalized pentiptycene derivatives are useful building blocks for the construction of new supramolecular hosts, such as pentiptycene-de- 


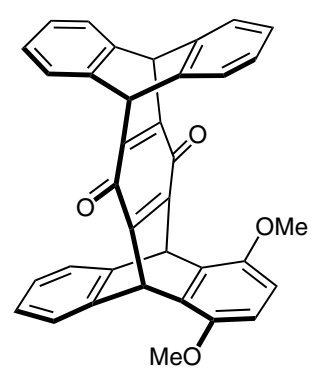

111

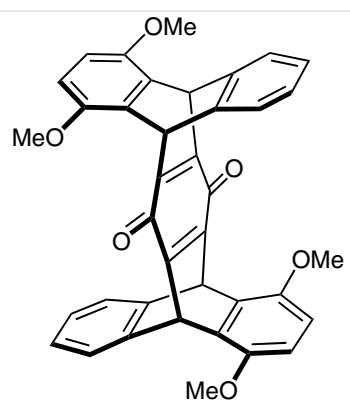

112

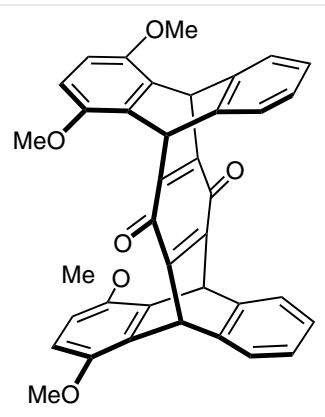

113

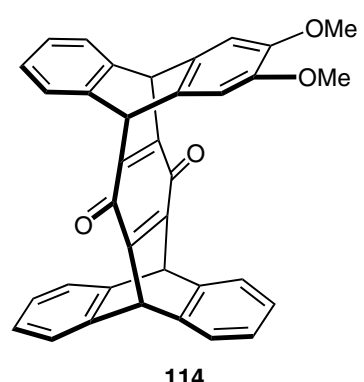

114

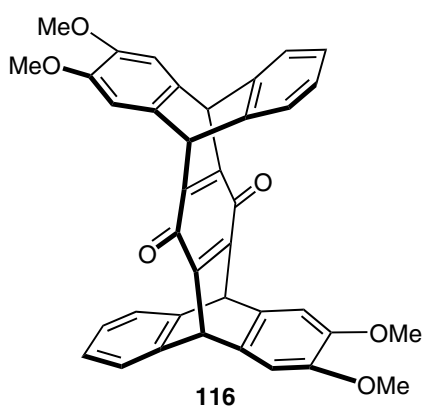

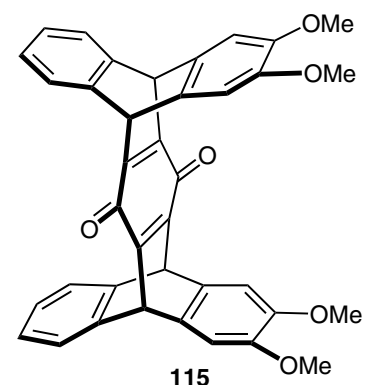

115

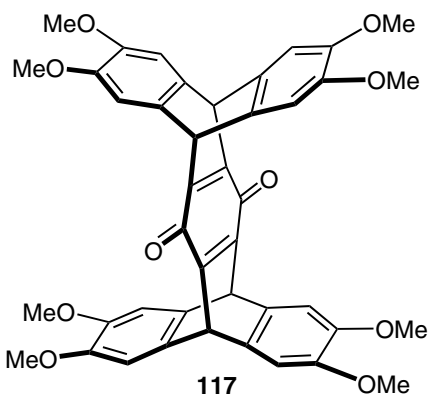

Figure 2 Structures of peripheral methoxy-substituted pentiptycene quinones

rived crown ethers ${ }^{5 \mathrm{~g}, 45}$ and pentiptycene-derived tweezerlike molecules incorporating nitrogen-containing heterocyclic rings, ${ }^{46}$ which might find wide applications in molecular recognition and assembly.

\section{Synthesis of Other Substituted Iptycenes}

Due to synthetic difficulties, few higher order iptycenes and their derivatives have been reported, and the majority have focused on the synthesis of iptycene quinone. In 1998,
Yang and Swager ${ }^{7 b}$ reported the synthesis of a tweezer-like noniptycene quinone. As shown in Scheme 35, the DielsAlder reaction between the triptycene quinone and pentacene gave a mixture of three semi-quinone adducts (two of which are shown). Subsequent treatment with glacial acetic acid in the presence of $\mathrm{HBr}$ and potassium bromate $\left(\mathrm{KBrO}_{3}\right)$ under reflux conditions gave the noniptycene diquinone 126 in 13\% yield, along with another extended pentiptycene 125. 
a)

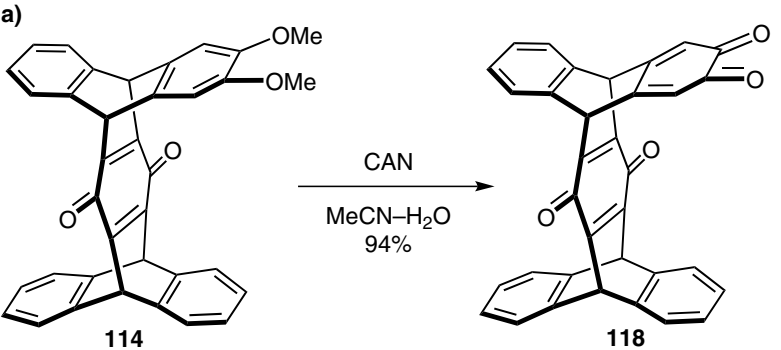

b)
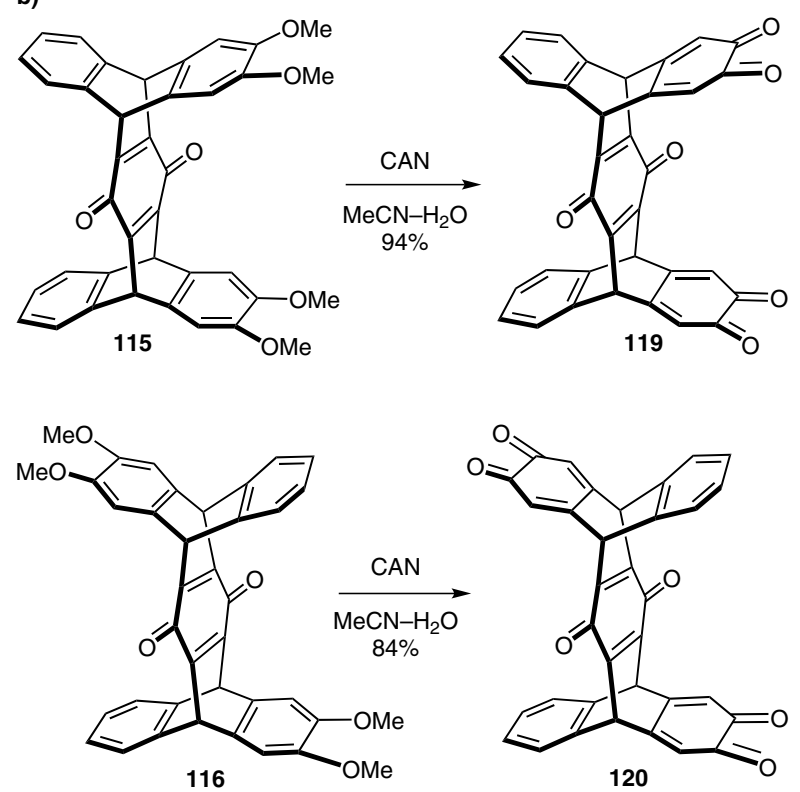

c)
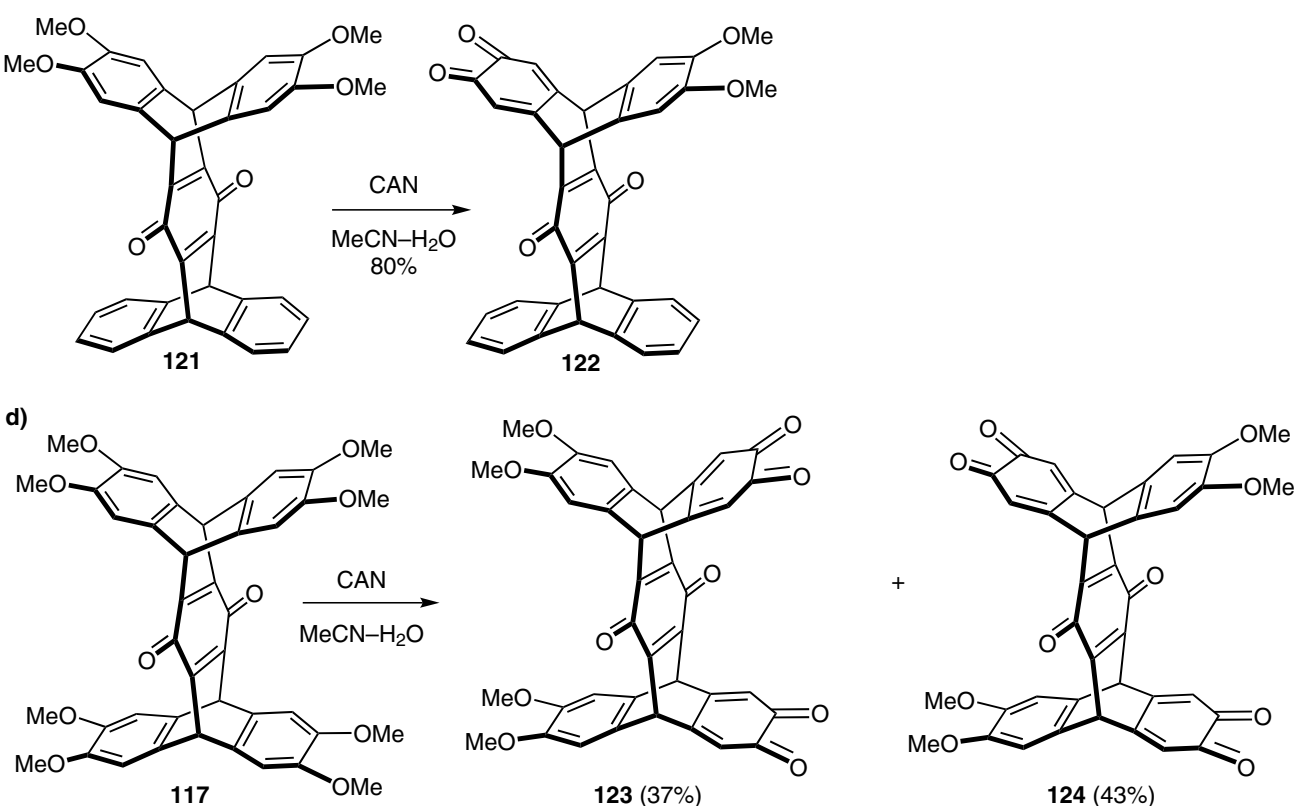

Scheme 34 Oxidations of peripheral methoxy-substituted pentiptycene quinones 

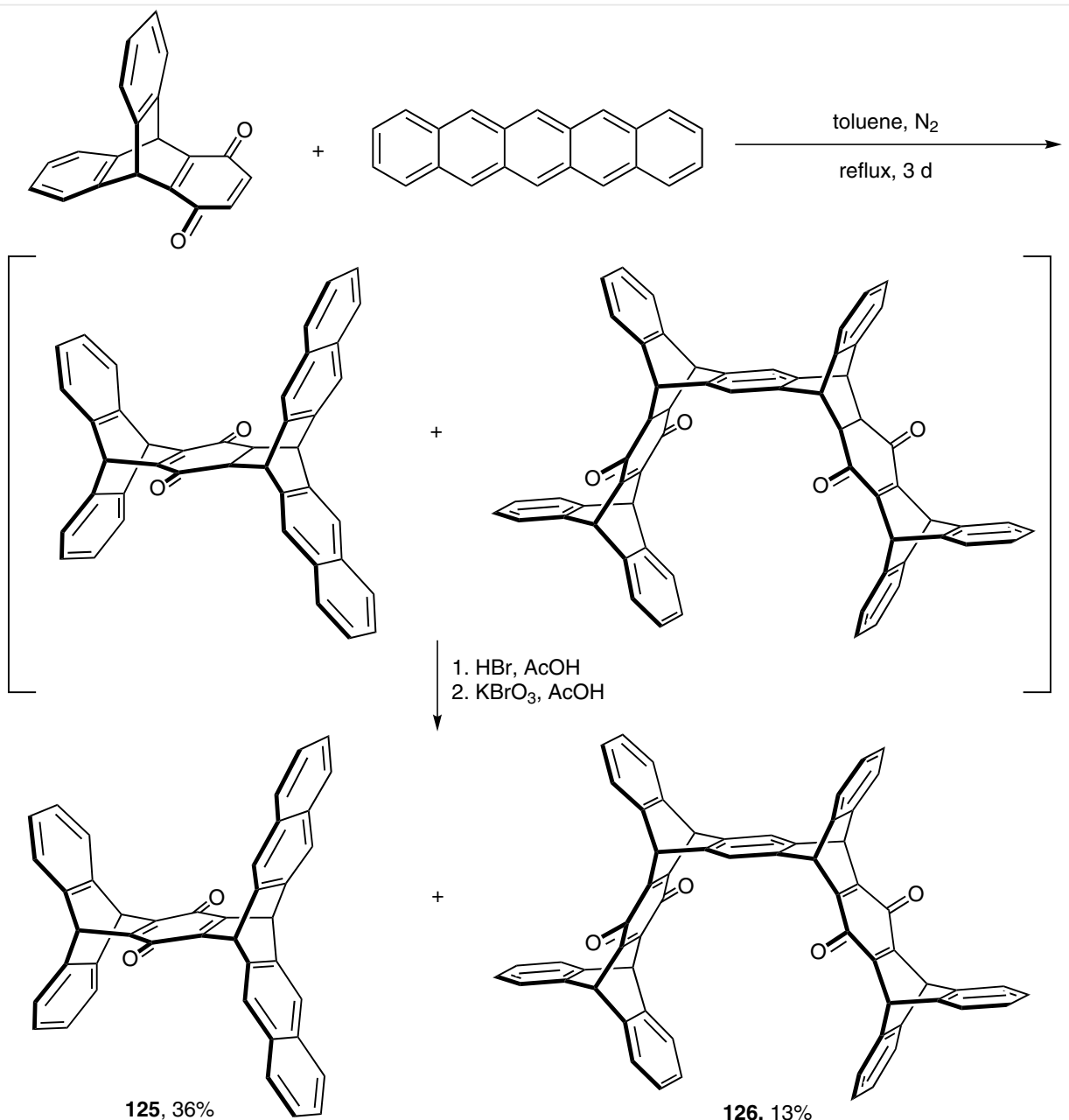

$126,13 \%$

Scheme 35 Synthesis of noniptycene quinone

Several years later, we reported a practical and efficient method $^{42}$ for the synthesis of a series of heptiptycene quinones, which contained U-shaped cavities. Either via the one-pot reaction of pentiptycene quinone $\mathbf{1 2 7}$ with anthracene in refluxing acetic acid in the presence of $p$-chloranil, or by the reaction of triptycene diquinone $\mathbf{1 2 8}$ with two equivalents of anthracene at reflux temperature in glacial acetic acid, heptiptycene diquinone $\mathbf{1 2 9}$ could be obtained in reasonable yields (Scheme 36).

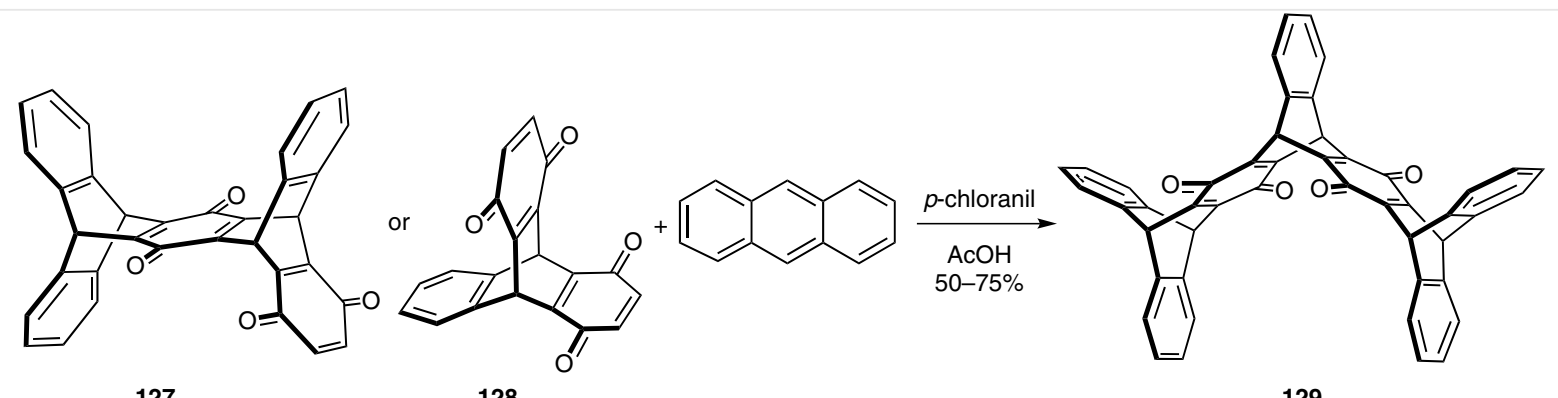

127

128

129

Scheme 36 Synthesis of heptiptycene diquinone 129 


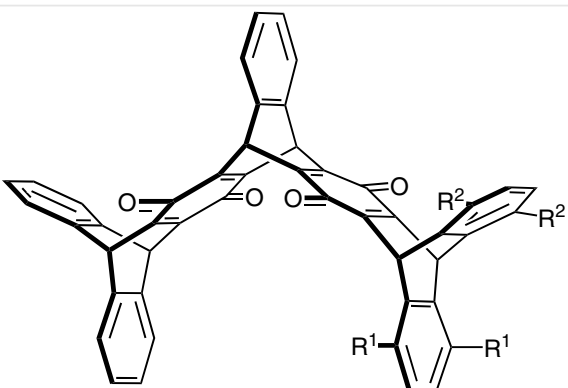

$130\left(R^{1}=\right.$ OMe, $\left.R^{2}=H\right)$

$131\left(R^{1}=\mathrm{H}, \mathrm{R}^{2}=\mathrm{OMe}\right)$

$132\left(R^{1}=R^{2}=\mathrm{OMe}\right)$

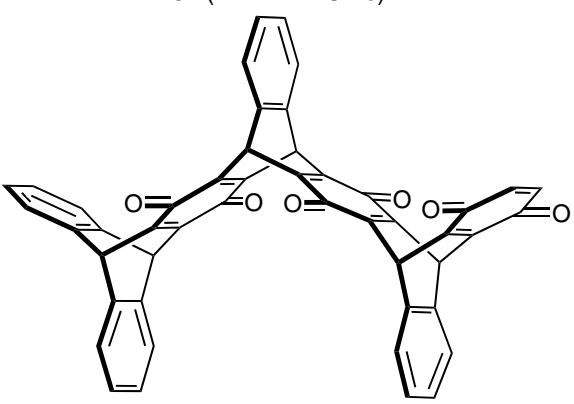

134
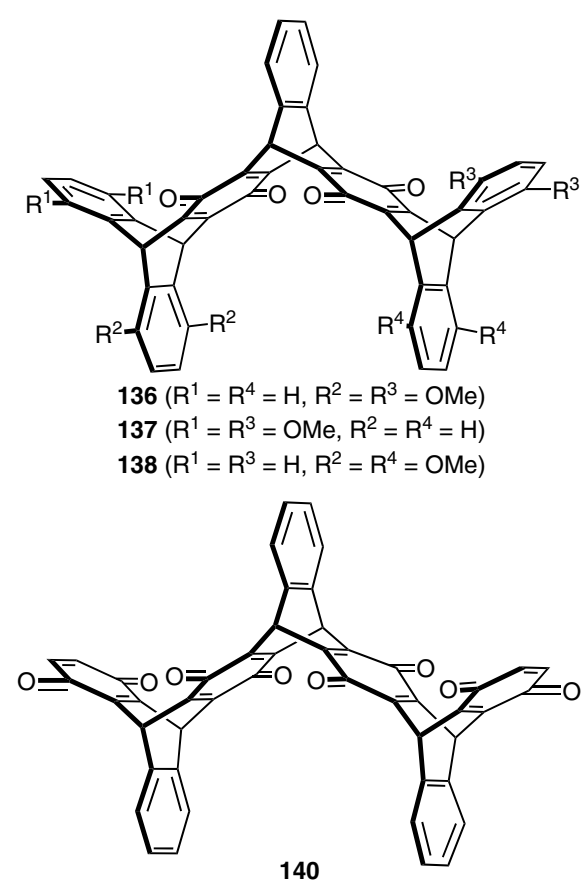

140

Figure 3 Structures of the synthesized heptiptycene quinones

When 1,4-dimethoxyanthracene was used instead of anthracene (in acetic acid in the presence of $p$-chloranil), a mixture of adducts 130 and 131 was obtained, which could be further oxidized by CAN to give the corresponding heptiptycene tri(p-quinone) 133. Using a similar strategy, we synthesized a series of heptiptycene quinones by the reac-

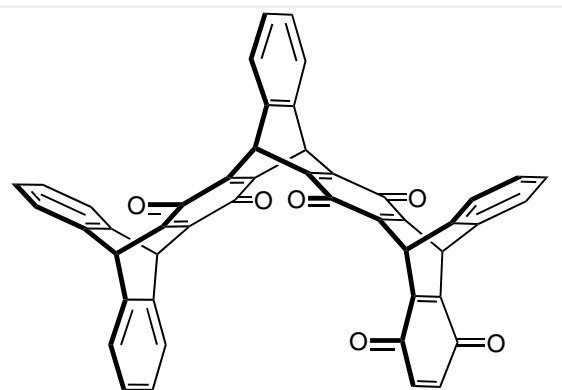

133

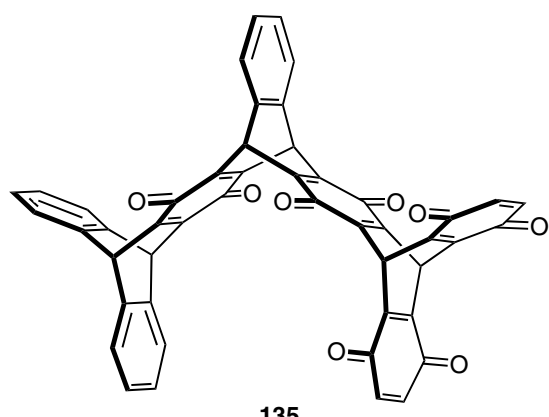

135

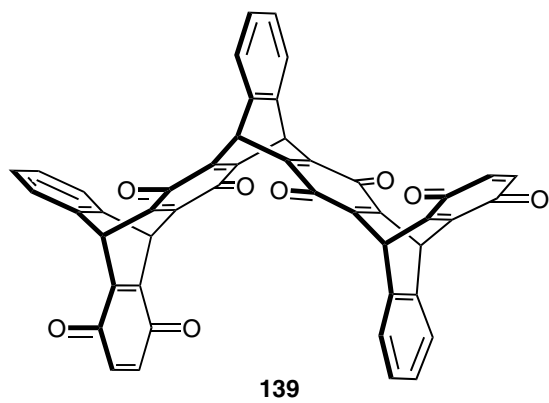

139

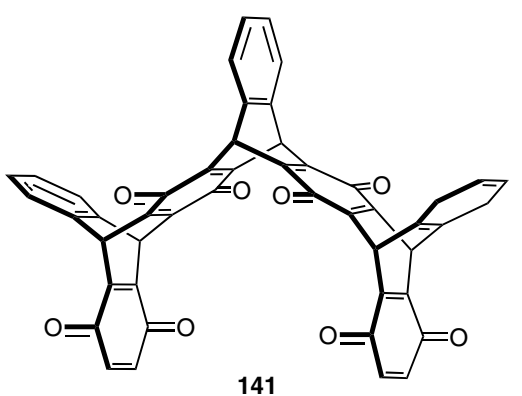

141

tion of pentiptycene quinones or triptycene quinones with anthracene or substituted anthracenes (Figure 3, compounds 132 and 134-141).

According to a similar method, we have also synthesized tweezer-shaped noniptycene triquinone 142 and heptiptycene triquinone 143, with three equivalent U-shaped cavities, and noniptycene triquinone 144 possessing two equiv- 


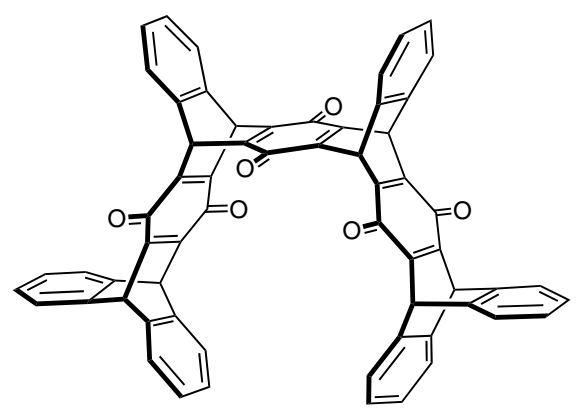

142

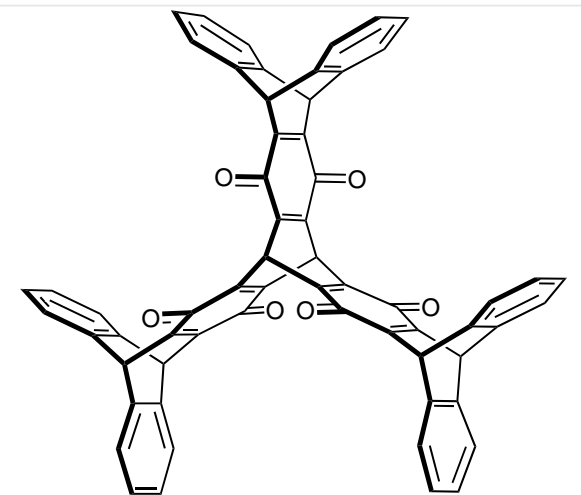

143

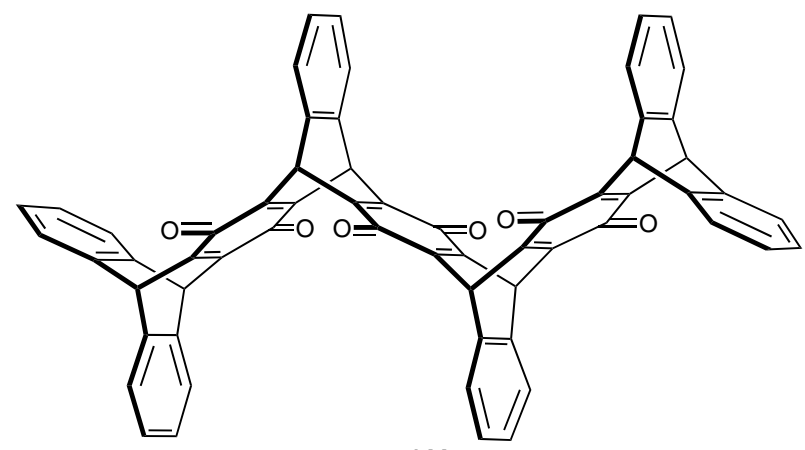

144

Figure 4 Structures of the synthesized iptycene tri(p-quinone)s

alent heptiptycene triquinone U-shaped cavities, in reasonable yields, by the addition reaction of pentiptycene triquinone with two equivalents of anthracene in acetic acid in the presence of $p$-chloranil (Figure 4).

Starting from 6,13-bis-(triisopropylsilylethynyl)pentacene and triptycene quinone, Zhao and Swager ${ }^{47}$ obtained noniptycene derivatives 145a,b and 146a,b (Figure 5), which contained both alkoxy and ethynyl substituents. These large and extended scaffolds might show potential as precursors for the synthesis of soluble conjugated polymers with specific structures and properties, and high solubility in common solvents.
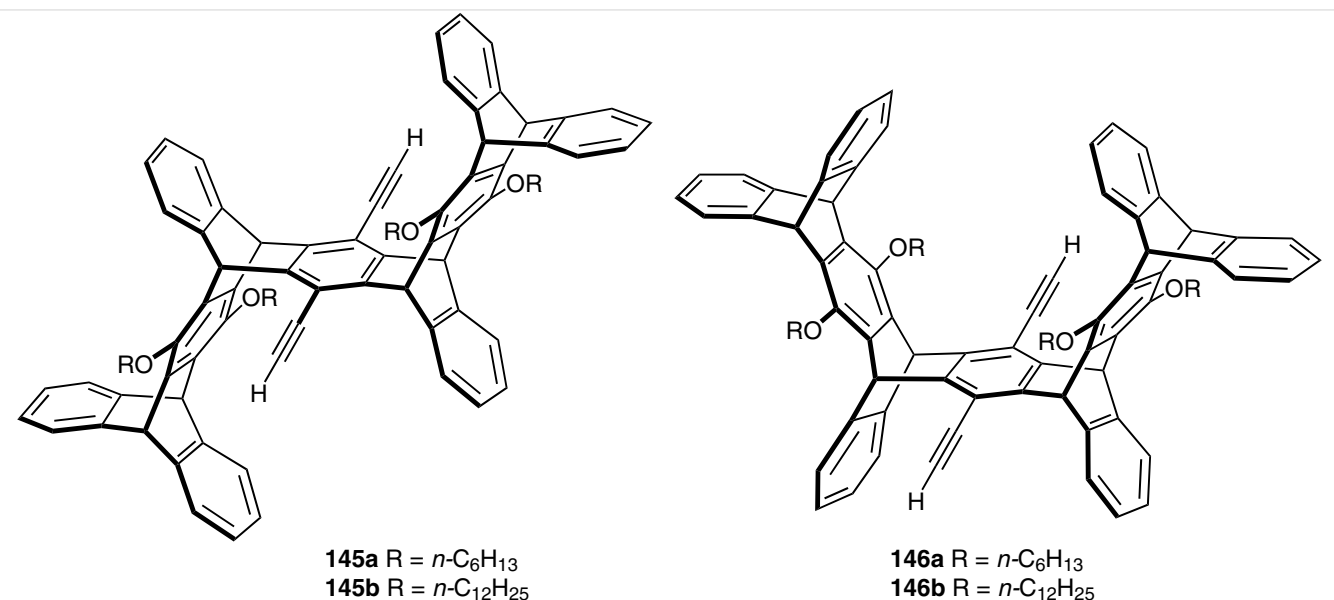

145a $\mathrm{R}=n-\mathrm{C}_{6} \mathrm{H}_{13}$
145b $\mathrm{R}=n-\mathrm{C}_{12} \mathrm{H}_{2}$

146a $\mathrm{R}=n-\mathrm{C}_{6} \mathrm{H}_{13}$

146b $\mathrm{R}=n-\mathrm{C}_{12} \mathrm{H}_{25}$

Figure 5 Structures of the synthesized noniptycene derivatives 145a,b and 146a,b 


\section{Conclusion and Outlook}

There are two main synthetic strategies for the synthesis of triptycene derivatives with useful functional groups. The direct Diels-Alder addition strategy involves a one-pot reaction demonstrating good suitability and scalability for many substituted triptycenes. However, the fact that the substrates (anthracenes or benzynes with specific substituents) are often difficult to prepare, and the formation of isomeric mixtures of products, both represent disadvantages to the wider application of the Diels-Alder strategy. To a certain degree, the selective derivatization of unsubstituted triptycene merely supplements these insufficiencies. Several important functional groups, such as acetyl, nitro and halo, can be introduced easily by properly chosen derivatization reactions. However, the strategies for selective derivatizations of the triptycene skeleton are still relatively demanding. Moreover, selective derivatization at the $\alpha$-position of triptycene, due to its low reactivity, remains a major challenge. Remarkable headway has been made toward the synthesis of substituted pentiptycenes, in particular, central-ring functionalized pentiptycenes. On the other hand, with the difficulties associated with stereoselectivity and regioselectivity, the aromatic electrophilic substitution of pentiptycene has not been reported to date. The situation for the other higher order iptycenes is even worse with only few reports being available. Thus, considerable challenges still exist in the synthesis of substituted iptycenes. In relation to their gradually increasing applications as molecular machines, and in supramolecular chemistry, materials science, and many other research areas, the synthesis of substituted iptycenes, which are the cornerstone of iptycene chemistry, is also filled with both challenges and opportunities.

\section{Acknowledgment}

We thank the National Natural Science Foundation of China (21332008, 51373180), and the National Basic Research Program (2011CB932501) of China, for financial support.

\section{References}

(1) Bartlett, P. D.; Ryan, M. J.; Cohen, S. G.J. Am. Chem. Soc. 1942, 64, 2649.

(2) (a) Swager, T. M. Acc. Chem. Res. 2008, 41, 1181. (b) Yang, J. S.; Yan, J. L. Chem. Commun. 2008, 1501. (c) Chong, J. H.; MacLachlan, M. J. Chem. Soc. Rev. 2009, 38, 3301. (d) Chen, C.-F.; Han, T.; Jiang, Y. Chin. Sci. Bull. 2007, 52, 1349. (e) Chen, C.-F. Chem. Commun. 2011, 47, 1674. (f) Han, Y.; Meng, Z.; Ma, Y.-X.; Chen, C.-F. Acc. Chem. Res. 2014, 47, 2026.

(3) Hart, H.; Bashirhashemi, A.; Luo, J.; Meador, M. A. Tetrahedron 1986, $42,1641$.

(4) (a) Kelly, T. R.; De Silva, H.; Silva, R. A. Nature 1999, 401, 150. (b) Chen, Y.-C.; Sun, W.-T.; Lu, H.-F.; Chao, I.; Huang, G.-J.; Lin,
Y.-C.; Huang, S.-L.; Huang, H.-H.; Lin, Y.-D.; Yang, J.-S. Chem. Eur. J. 2011, 17, 1193. (c) Yang, C.-H.; Prabhakar, C.; Huang, S.-L.; Lin, Y.-C.; Tan, W.-S.; Misra, N. C.; Sun, W.-T.; Yang, J.-S. Org. Lett. 2011, 13, 5632. (d) Sun, W.-T.; Huang, S.-L.; Yao, H.-H.; Chen, I.C.; Lin, Y.-C.; Yang, J.-S. Org. Lett. 2012, 14, 4154. (e) Meng, Z.; Xiang, J.; Chen, C.-F. Chem. Sci. 2013, 5, 1520. (f) Ma, Y.-X.; Meng, Z.; Chen, C.-F. Org. Lett. 2014, 16, 1860. (g) Jiang, Y.; Guo, J.-B.; Chen, C.-F. Org. Lett. 2010, 12, 4248. (h) Jiang, Y.; Guo, J.-B.; Chen, C.-F. Chem. Commun. 2010, 46, 5536.

(5) (a) Ma, Y.-X.; Han, Y.; Cao, J.; Chen, C.-F. Org. Biomol. Chem. 2013, 11, 8183. (b) Han, Y.; Cao, J.; Li, P.-F.; Zong, Q.-S.; Zhao, J.M.; Guo, J.-B.; Xiang, J.-F.; Chen, C.-F. J. Org. Chem. 2013, 78, 3235. (c) Zhu, X.-Z.; Chen, C.-F. J. Am. Chem. Soc. 2005, 127, 13158. (d) Zhang, C.; Chen, C.-F. J. Org. Chem. 2007, 72, 9339. (e) Cao, J.; Jiang, Y.; Zhao, J.-M.; Chen, C.-F. Chem. Commun. 2009, 1987. (f) Zhao, J.-M.; Zong, Q.-S.; Han, T.; Xiang, J.-F.; Chen, C.-F. J. Org. Chem. 2008, 73, 6800. (g) Han, Y.; Jiang, Y.; Chen, C.-F. Chin. Chem. Lett. 2013, 24, 475.

(6) (a) Long, T. M.; Swager, T. M. Adv. Mater. 2001, 13, 601. (b) Zhu, Z.-G.; Swager, T. M. J. Am. Chem. Soc. 2002, 124, 9670. (c) Ohira, A.; Swager, T. M. Macromolecules 2007, 40, 19. (d) Ghanem, B. S.; Msayib, K. J.; McKeown, N. B.; Harris, K. D. M.; Pan, Z.; Budd, P. M.; Butler, A.; Selbie, J.; Book, D.; Walton, A. Chem. Commun. 2007, 67. (e) Zhang, G.; Presly, O.; White, F.; Oppel, I. M.; Mastalerz, M. Angew. Chem. Int. Ed. 2014, 53, 1516. (f) Zhang, G.; Presly, O.; White, F.; Oppel, I. M.; Mastalerz, M. Angew. Chem. Int. Ed. 2014, 53, 5126. (g) Kohl, B.; Rominger, F.; Mastalerz, M. Org. Lett. 2014, 16, 704. (h) Schneider, M. W.; Hauswald, H. J. S.; Stoll, R.; Mastalerz, M. Chem. Commun. 2012, 48, 9861. (i) Schneider, M. W.; Oppel, I. M.; Griffin, A.; Mastalerz, M. Angew. Chem. Int. Ed. 2013, 52, 3611. (j) Mastalerz, M.; Schneider, M. W.; Oppel, I. M.; Presly, O. Angew. Chem. Int. Ed. 2011, 50, 1046. (k) Mastalerz, M.; Oppel, I. M. Angew. Chem. Int. Ed. 2012, 51, 5252. (1) Carta, M.; Croad, M.; Malpass-Evans, R.; Jansen, J. C.; Bernardo, P.; Clarizia, G.; Friess, K.; Lanč, M.; McKeown, N. B. Adv. Mater. 2014, 26, 3526. (m) Ghanem, B. S.; Hashem, M.; Harris, K. D. M.; Msayib, K. J.; Xu, M.; Budd, P. M.; Chaukura, N.; Book, D.; Tedds, S.; Walton, A.; McKeown, N. B. Macromolecules 2010, 43, 5287. (n) Kahveci, Z.; Islamoglu, T.; Shar, G. A.; Ding, R.; El-Kaderi, H. M. CrystEngComm 2013, 15, 1524. (o) Rabbani, M. G.; Reich, T. E.; Kassab, R. M.; Jackson, K. T.; El-Kaderi, H. M. Chem. Commun. 2012, 48, 1141. (p) Taylor, R. G. D.; Carta, M.; Bezzu, C. G.; Walker, J.; Msayib, K. J.; Kariuki, B. M.; McKeown, N. B. Org. Lett. 2014, 16, 1848. (q) Crane, A. K.; Wong, E. Y. L.; MacLachlan, M. J. CrystEngComm 2013, 15, 9811.

(7) (a) Yang, J.-S.; Swager, T. M. J. Am. Chem. Soc. 1998, 120, 5321. (b) Yang, J.-S.; Swager, T. M. J. Am. Chem. Soc. 1998, 120, 11864. (c) Yamaguchi, S.; Swager, T. M. J. Am. Chem. Soc. 2001, 123, 12087. (d) Amara, J. P.; Swager, T. M. Macromolecules 2005, 38, 9091. (e) Hu, S.-Z.; Chen, C.-F. Org. Biomol. Chem. 2011, 9, 5838. (f) Zhao, J.-M.; Zong, Q.-S.; Chen, C.-F. J. Org. Chem. 2010, 75, 5092. (g) Brutschy, M.; Schneider, M. W.; Mastalerz, M.; Waldvogel, S. R. Adv. Mater. 2012, 24, 6049. (h) Brutschy, M.; Schneider, M. W.; Mastalerz, M.; Waldvogel, S. R. Chem. Commun. 2013, 49, 8398.

(8) (a) Gung, B. W.; Emenike, B. U.; Lewis, M.; Kirschbaum, K. Chem. Eur. J. 2010, 16, 12357. (b) Mati, I. K.; Cockroft, S. L. Chem. Soc. Rev. 2010, 39, 4195. (c) Xue, M.; Su, Y.-S.; Chen, C.-F. Chem. Eur. J. 2010, 16, 8537. (d) Xue, M.; Chen, C.-F. Chem. Commun. 2011, 47, 2318. (e) Su, Y.-S.; Liu, J.-W.; Jiang, Y.; Chen, C.-F. Chem. Eur. J. 2011, 17, 2435.

(9) Wittig, G.; Ludwig, R. Angew. Chem. 1956, 68, 40. 
(10) (a) Cadogan, J. I. G.; Hibbert, P. G. Proc. Chem. Soc. 1964, 338. (b) Cadogan, J. I. G.; Cook, J.; Harger, M. J. P.; Hibbert, P. G.; Sharp, J. T. J. Chem. Soc. B 1971, 595.

(11) (a) Brewer, J. P. N.; Eckhard, I. F.; Heaney, H.; Marples, B. A. J. Chem. Soc. C 1968, 664. (b) Heaney, H.; Jablonski, J. M. J. Chem. Soc. C 1968, 1895.

(12) Cadogan, J. I. G.; Harger, M. J. P.; Sharp, J. T. J. Chem. Soc. B 1971, 602.

(13) Zyryanov, G. V.; Palacios, M. A.; Anzenbacher, P. Org. Lett. 2008, 10, 3681.

(14) Mori, I.; Kadosaka, T.; Sakata, Y.; Misumi, S. Bull. Chem. Soc. Jpn. 1971, 44, 1649 .

(15) Klanderman, B. H.; Criswell, T. R. J. Org. Chem. 1969, 34, 3426.

(16) Rogers, M. E.; Averill, B. A. J. Org. Chem. 1986, 51, 3308.

(17) Zhao, J.-M.; Lu, H.-Y.; Cao, J.; Jiang, Y.; Chen, C.-F. Tetrahedron Lett. 2009, 50, 219.

(18) Marks, V.; Nahmany, M.; Gottlieb, H. E.; Biali, S. E. J. Org. Chem. 2002, 67, 7898 .

(19) (a) Rybackova, M.; Belohradsky, M.; Holy, P.; Pohl, R.; Zavada, J. Synthesis 2006, 2039. (b) Rybacek, J.; Rybackova, M.; Hoj, M.; Belohradsky, M.; Holy, P.; Kilsa, K.; Nielsen, M. B. Tetrahedron 2007, 63, 8840. (c) Rybackova, M.; Belohradsky, M.; Holy, P.; Pohl, R.; Dekoj, V.; Zavada, J. Synthesis 2007, 1554.

(20) Zonta, C.; De Lucchi, O.; Linden, A.; Lutz, M. Molecules 2010, 15, 226.

(21) Lu, J.; Zhang, J. J.; Shen, X.-F.; Ho, D. M.; Pascal, R. A. J. Am. Chem. Soc. 2002, 124, 8035.

(22) Friedman, L.; Logullo, F. M. J. Am. Chem. Soc. 1963, 85, 1549.

(23) Paget, C. J.; Burger, A. J. Org. Chem. 1965, 30, 1329.

(24) Skvarchenko, V. R.; Shalaev, V. K.; Klabunovsk, E. I. Russ. Chem. Rev. 1974, 43, 951.

(25) Li, P.-F.; Chen, C.-F. J. Org. Chem. 2012, 77, 9250.

(26) Zhang, C.; Chen, C.-F. J. Org. Chem. 2007, 72, 3880.

(27) Klanderm, B. H.; Perkins, W. C. J. Org. Chem. 1969, 34, 630.

(28) Shigeru, T.; Ryusei, K. J. Am. Chem. Soc. 1973, 95, 4976.
(29) (a) Hartshorn, S. R.; Moodie, R. B.; Schofield, K. J. Chem. Soc. B 1971, 1256. (b) Terabe, S.; Konaka, R. J. Am. Chem. Soc. 1973, 95, 4976. (c) Rees, J. H. J. Chem. Soc., Perkin Trans. 2 1975, 945. (d) Streitwieser, A.; Ziegler, G. R.; Mowery, P. C.; Lewis, A.; Lawler, R. G. J. Am. Chem. Soc. 1968, 90, 1357.

(30) (a) Chong, J. H.; MacLachlan, M. J. Inorg. Chem. 2006, 45, 1442. (b) Chong, J. H.; MacLachlan, M. J. J. Org. Chem. 2007, 72, 8683.

(31) Zhang, C.; Chen, C.-F. J. Org. Chem. 2006, 71, 6626.

(32) Dahms, K.; Senge, M. O. Tetrahedron Lett. 2008, 49, 5397.

(33) Chen, Z.; Swager, T. M. Macromolecules 2008, 41, 6880.

(34) Mastalerz, M.; Sieste, S.; Cenić, M.; Oppel, I. M. J. Org. Chem. 2011, 76, 6389.

(35) Ballester, M.; Riera-Figueras, J.; Castaner, J.; Badfa, C.; Monso, J. M. J. Am. Chem. Soc. 1971, 93, 2215.

(36) Ballester, M.; Molinet, C.; Castañer, J. J. Am. Chem. Soc. 1960, 82, 4254.

(37) Šket, B.; Zupan, M. Bull. Chem. Soc. Jpn. 1981, 54, 279.

(38) Hilton, C. L.; Jamison, C. R.; Zane, H. K.; King, B. T. J. Org. Chem. 2008, 74, 405.

(39) Skvarchenko, V. R.; Getmanova, E. V.; Skvarchenko, V. R. Zh. Org. Khim. 1976, 12, 191.

(40) Hart, H.; Shamouilian, S.; Takehira, Y. J. Org. Chem. 1981, 46, 4427.

(41) (a) Hart, H. Pure Appl. Chem. 1993, 65, 27. (b) Wiehe, A.; Senge, M. O.; Kurreck, H. Lieb. Ann. 1997, 1951. (c) Williams, V. E; Swager, T. M. Macromolecules 2000, 33, 4069. (d) Spyroudis, S.; Xanthopoulou, N. Tetrahedron Lett. 2003, 44, 3767.

(42) Zhu, X.-Z.; Chen, C.-F. J. Org. Chem. 2005, 70, 917.

(43) (a) Yang, J.-S.; Ko, C.-W. J. Org. Chem. 2006, 71, 844. (b) Yang, J.S.; Yan, J.-L. Chem. Commun. 2008, 1501. (c) Yang, J.-S.; Yan, J.-L.; Jin, Y.-X.; Sun, W.-T.; Yang, M.-C. Org. Lett. 2009, 11, 1429.

(44) Cao, J.; Lu, H.-Y.; Chen, C.-F. Tetrahedron 2009, 65, 8104.

(45) (a) Cao, J.; Lu, H.-Y.; You, X.-J.; Zheng, Q.-Y.; Chen, C.-F. Org. Lett. 2009, 11, 4446. (b) Cao, J.; Lu, H.-Y.; Xiang, J.-F.; Chen, C.-F. Chem. Commun. 2010, 46, 3586. (c) Han, Y.; Guo, J.-B.; Cao, J.; Chen, C.-F. Tetrahedron 2013, 69, 4541.

(46) Cao, J.; Zhu, X.-Z.; Chen, C.-F. J. Org. Chem. 2010, 75, 7420.

(47) Zhao, D.-H.; Swager, T. M. Org. Lett. 2005, 7, 4357. 